Sharif University of Technology
Scientia Iranica
SCIENTIA
I RAN I C A

\title{
Dynamic behavior of large-diameter piles considering liquefaction under clay layer
}

\author{
M. Oliaei* and S.M.A. Ghotbi Siabil \\ Department of Civil Engineering, Tarbiat Modares University, Tehran, Iran.
}

Received 4 May 2015; received in revised form 18 April 2016; accepted 29 August 2016

\section{KEYWORDS}

Numerical

investigation;

Soil-pile interaction;

Large-diameter piles;

Liquefaction;

Clay layer.

\begin{abstract}
Marine structures are mostly constructed on deep foundations, namely largediameter piles. Such support structures are driven into deposits of saturated granular soil, vulnerable to liquefaction under loadings of dynamic nature, e.g. earthquakes. Although numerous studies have been accomplished to obtain a comprehensive understanding of their performance during liquefaction, a conclusive study has not been presented for the specific case of large-diameter piles under a clay layer. This issue has great importance in the case of offshore wind turbines, since they are very sensitive to dynamic loadings. In this study, a 3D FEM model was constructed by OpenSeesPL to explore soil and pile responses throughout liquefaction. To capture the precise behavior, a constitutive law based on a multi-surface plasticity was utilized for soil. The described model used in this study is capable of accurate prediction of sand behavior in undrained conditions. Different scenarios were tested: variations in pile dimensions, loading frequency, and influence of clay layer. Sensitivity analyses show that loading frequency, presence of clay layer, and pile diameter could significantly affect the behavior of large-diameter piles in saturated soil conditions.
\end{abstract}

(C) 2017 Sharif University of Technology. All rights reserved.

\section{Introduction}

Marine environments, including offshore and nearshore areas, river paths, and their neighboring banks, are typically covered with loose deposits of saturated soil. Wharves, bridges, and recently wind turbines are among the most popular structures constructed at these regions, which are also likely to encounter the strike of an earthquake. It is well known that when saturated granular soil is exposed to a dynamic loading, such as a seismic wave, occurrence of liquefaction and consequent loss in shear strength of soil is highly probable in most cases. Therefore, the mentioned structures are prone to failure or collapse because of

*. Corresponding author. Tel.: +982182884395 E-mail addresses: m.olyaei@modares.ac.ir (M. Oliaei); amin.ghotbi@modares.ac.ir (S.M.A. Ghotbi Siabil)

doi: $10.24200 /$ sci. 2017.4170 possible foundation inefficiency in the liquefied soil. Some instances of destruction and failure of structures in the mentioned conditions are observed during the earthquakes of Niigata (1964), Alaska (1964), LomaPrietta (1989), and Kobe (1995). An example of tilting and damage in the pile foundation of a wharf resulted from a liquefaction event is shown in Figure 1.

Thus, offshore/nearshore structures are built over saturated soil consisting of sand and cohesive material of low consistency, deposited along shore lines with variables advancing into the water covered area. They are normally built over piled foundations with large diameters in order to transfer superstructure's load to denser layers of the soil in a reliable way. Diameter of the previously mentioned piles is typically greater than $1 \mathrm{~m}$, generally larger than those of ordinary structures are. These piles are significantly appropriate for resisting large bending moments and could be categorized as large-diameter piles. The coincidence of using large-diameter pile and existence of cohesive 


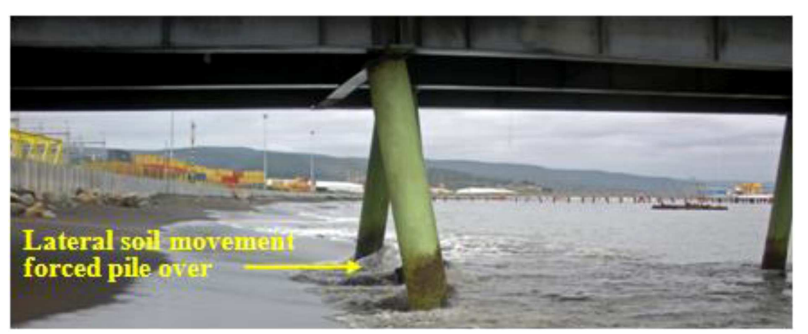

Figure 1. Bending and displacement of pile foundation at Puerto de Coronel Muelle wharf [1].

materials covering loose granular material on the sea floor in offshore and nearshore zones could introduce unknown aspects to dynamic behavior of such piles; therefore, demands are to be investigated with greater deliberation.

The aim of this research effort is to study response of large-diameter piles in different scenarios for offshore applications. The large magnitude of pile's diameter and the subsequent increase in the side area of pile along with kinematic forces of the soil are likely to influence the mechanisms affecting its behavior. Moreover, effect of a soft layer of clay has not been completely understood on the liquefaction phenomena either, especially through numerical analyses. To achieve this understanding, several parametric studies were conducted on two possible cases of the configuration in soil layering. These cases are termed Case I, including only two layers of sand with different relative densities, and Case II composed of two sand layers covered with a deposit of highly soft clay. Most of the parametric studies were based on the comparison between these two cases to achieve a comprehensive understanding of the mentioned issue.

\section{Literature review}

Many researchers have made efforts to study the nature of soil liquefaction and its influence on the behavior of structural foundations. In general, these studies can be classified into experimental and numerical studies. Experimental research also includes those performed in field or laboratory.

For experimental studies' section, a number of recently accomplished research studies are mentioned here briefly. Wilson [2] conducted a series of centrifuge tests on piles and their super structures in liquefiable soil. They realized that seismic response of a soilpile-superstructure is related to soil type, nature of earthquake, and the soil displacements. In addition to that, several studies have been conducted by Kamijo et al. [3], Yao et al. [4], Tokimatsu et al. [5], Dunga et al. [6], Tamura \& Tokimatsu [7], Han et al. [8], Haeri et al. [9], and Brandenberg et al. [10].

Robust numerical methods are the powerful and economical means to capture behavior of complicated systems. In addition to the referred experimental efforts, numerical studies have been carried out by various codes and platforms. Some notable instances of such studies include: Finn et al. [11], Tabesh \& Poulos [12], Miyazaki et al. [13], Finn and Fujita [14], Klar et al. [15], Liyanapathirana and Poulos [16,17], Chang et al. [18], Bhattacharya et al. [19], Elgamal et al. [20], Cheng and Jeremic [21], Cubrinovski et al. [22], Rahmani and Pak [23], Asgari and Oliaei [24], Sarkar et al. [25], Bouckovalas and Chaloulos [26], Asadi and Sharifipour [27], and Lin et al. [28].

Elgamal and Yang [29] carried out several numerical simulations to investigate behavior of sand boils and their influencing factors, i.e. effect of a layer of clay. They discovered that due to very low permeability of clay covering sandy bed, rapid dissipation of excess Pore Water Pressure (PWP) is delayed and the sand can turn into a water interface and remain liquefied for a long period after earthquake. The shear strength of thin layer used in their study was even lower than static driving shear stress.

Meanwhile, there is a clear lack of research on effect of sand boil under clay layer in different situations, especially in the case of large-diameter piles. Hence, influences of sand liquefaction and boil under a thin clay layer and its effect on the behaviour of a large-diameter pile were investigated here in detail.

\section{Numerical framework and constitutive model}

The plasticity model used in this study was developed by Parra [30] and Yang [31] based on the original framework of Prevost [32], in which a multi-surface approach is adopted for cyclic hysteretic response [33,34]. Yield function, $f$, (Figure 2 ) is selected in the following form [32]:

$$
\begin{aligned}
f= & \frac{3}{2}\left(s-\left(p^{\prime}+p_{0}^{\prime}\right) \alpha\right):\left(s-\left(p^{\prime}+p_{0}^{\prime}\right) \alpha\right) \\
& -m^{2}\left(p^{\prime}+p_{0}^{\prime}\right)=0 .
\end{aligned}
$$

In the domain of $p^{\prime} \geq 0$, where $s=\sigma^{\prime}-p^{\prime} \delta$ is the deviatoric stress tensor, $p^{\prime}$ is mean effective stress, and

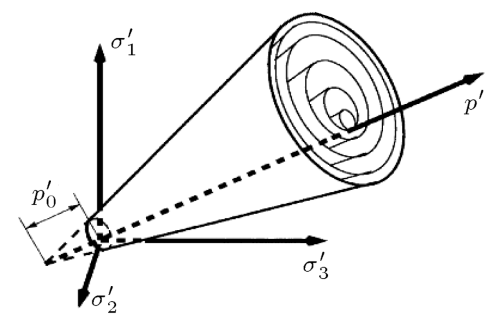

Principal effective stress space

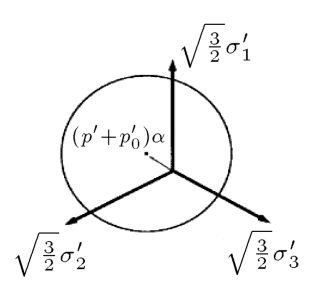

Deviatoric plane
Figure 2. Conical yield surface in principal stress space and deviatoric plane [31]. 
$p_{0}^{\prime}$ is a small positive constant, such that the yield surface size remains finite at $p^{\prime}=0$. Parameter $\alpha$ is the second-order kinematic deviatoric tensor defining the yield surface coordinates and $\mathrm{m}$ dictates the yield surface size [35].

The behavior of sandy soil is dependent on soil's relative density and in-situ stresses. Therefore, the selected constitutive law must be capable of taking into account the changes in the soil behavior with variations in its initial characteristics. Among different plastic constitutive laws presented for sandy soils [36], the multi-yield surface plasticity model has been selected in this research. This model can predict the real behavior of sand in experiments accurately [37]. In this model, emphasis is placed on controlling the magnitude of permanent shear strain accumulation in sands, which is important for the evaluation of failure. The contractive, perfectly plastic and dilative phases of Figure 3 are incorporated by developing a new appropriate flow rule. Therefore, this constitutive model is accurate according to the examples and papers provided by Elgamal et al. [38]. Its calibration data are also provided. There are 10 parameters in the model, which are calibrated for different stiffness in sand provided in the same reference and can be assigned by the user.

For solving the governing equations of the fully coupled soil-fluid medium, the matrix form of formulation is as follows:

$$
\begin{aligned}
& M \ddot{U}+\int_{v} B^{T} \sigma^{\prime} d V-Q P-f^{(s)}=0, \\
& Q^{T} \dot{U}+H P+S \dot{P}-f^{(p)}=0 .
\end{aligned}
$$

In these equations, $M, B, Q, S$, and $H$ are matrices
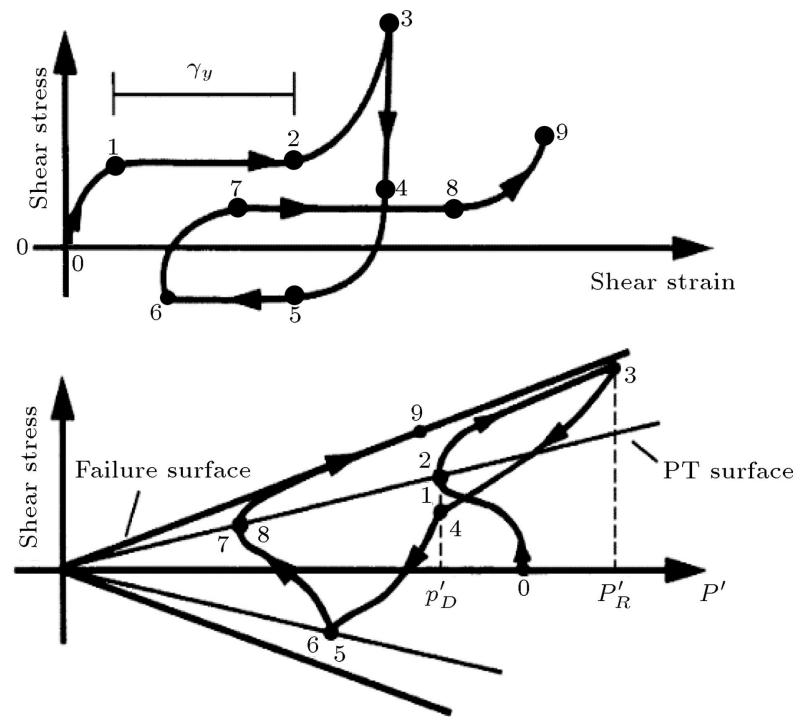

Figure 3. Schematic of constitutive model response showing shear stress, effective confinement, and strain relationship [31]. of mass, strain-displacement, coupling, compressibility, and permeability, respectively. Vectors $f^{(s)}$ and $f^{(p)}$ dictate the boundary conditions of model including body and surface forces in soil and fluid.

\section{Description and vertification of the numerical model}

Numerical model was created using finite-element program OpenSeesPL [38,39]. Based on the sensitivity analyses, dimensions of the model in $x, y$, and $z$ directions were selected 60,30 , and $35 \mathrm{~m}$, respectively, which are appropriate to minimize boundary effects. For the zone around the pile, mesh size was selected relatively fine, which becomes coarser by moving to the boundaries. By considering symmetry shown in Figure 4 and for the sake of simplicity and lower usage of resources, only half of the soil domain was modeled.

Two general cases were considered as representatives for common configuration of soil layers in marine environments. As illustrated in Figure 5, Case I consists of two layers of sand with thicknesses $(T h)$ of $8 \mathrm{~m}$ and $27 \mathrm{~m}$ and Relative Densities (Dr) equal to $40 \%$ and $70 \%$, respectively. For Case II as shown in Figure 6, half of the upper sand layer was replaced with very soft clay, and the characteristics of the rest of the

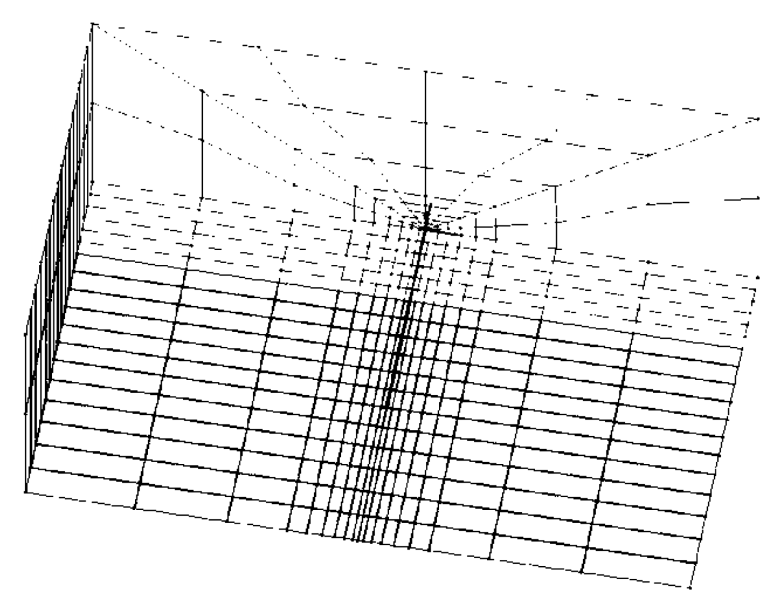

Figure 4. 3D FEM model used in this study.

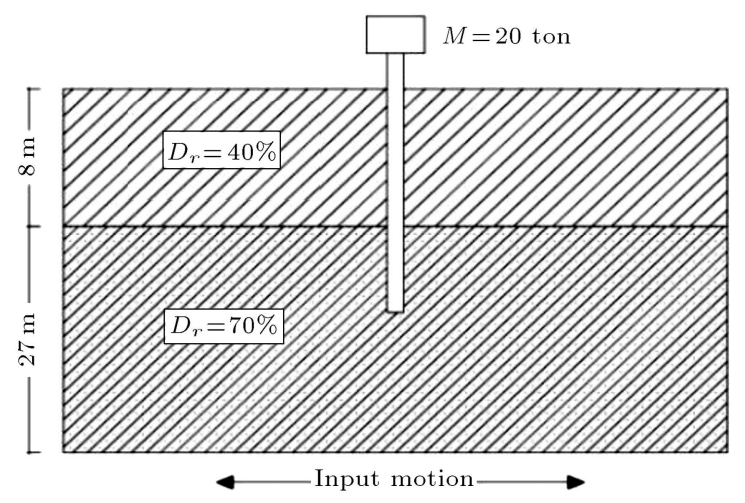

Figure 5. Schematic of Case I. 
Table 1. Values of model parameters for sand.

\begin{tabular}{lcc}
\hline \multirow{2}{*}{ Model parameters } & \multicolumn{2}{c}{ Value for: } \\
& $\boldsymbol{D}_{\boldsymbol{r}}=\mathbf{7 0 \%}$ & $\boldsymbol{D}_{\boldsymbol{r}}=\mathbf{4 0 \%}$ \\
\hline Reference shear modulus (kPa) & $13 \times 10^{4}$ & $9 \times 10^{4}$ \\
Reference bulk modulus (kPa) & $26 \times 10^{4}$ & $22 \times 10^{4}$ \\
Friction angle (degree) & 36.6 & 32 \\
Phase transformation angle (degree) & 26 & 26 \\
Contraction parameter 1 & 0.013 & 0.067 \\
Contraction parameter 2 & 0 & 0.23 \\
Dilation parameter 1 & 0.3 & 0.06 \\
Dilation parameter 2 & 0 & 0.27 \\
Peak shear strain (\%) & 10 & 10 \\
Permeability (m/s) & $6.6 \times 10^{-5}$ & $6.6 \times 10^{-5}$ \\
\hline
\end{tabular}

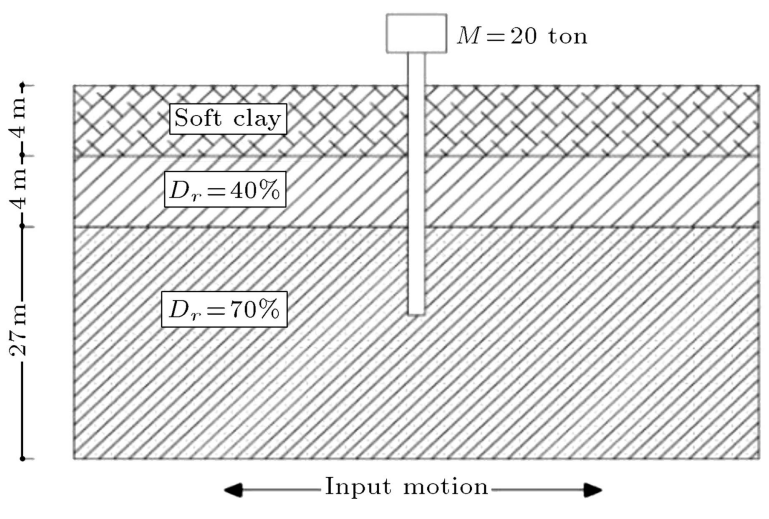

Figure 6. Schematic of Case II.

model were the same as for Case I. Parameters of sand used in the constitutive law for the two cases are shown in Table 1. For very soft clay, shear modulus is chosen to be as low as $1000 \mathrm{kPa}$ and cohesion is selected equal to $15 \mathrm{kPa}$.

OpenSeesPL uses Brick_Up elements for such analyses automatically, every node of which has 4 Degrees Of Freedom (DOFs). The first three DOFs represent soil translation in $x, y$, and $z$ directions, and the 4 th DOF represents PWP. Nodes were completely fixed at the base of the model. The 4th degree of freedom in the nodes on the ground surface was fixed to let water drain from this region. It was set "open" in the rest of the nodes in order for PWP to vary in them freely. At boundaries perpendicular to the direction of the base motion, nodes were fixed in perpendicular direction and were set free parallel to the direction of wave propagation. Nodes at the boundaries parallel to base excitation were constrained perpendicular to the excitation direction and were set free to move in the motion direction. To prevent reflection of dynamic waves from boundaries of the model, mesh size at boundaries was selected relatively larger than its size at regions close to the piles. It was also considered that in dynamic analysis, the
Table 2. Values of pile parameters.

\begin{tabular}{lc}
\hline Pile parameter & Value \\
\hline Diameter $(\mathrm{m})$ & 1 \\
Length $(\mathrm{m})$ & 21 \\
Free length $(\mathrm{m})$ & 1 \\
Thickness $(\mathrm{cm})$ & 1 \\
Elasticity modulus (GPa) & 30 \\
Superstructure mass (ton) & 20 \\
Pile head condition & Pinned \\
\hline
\end{tabular}

size of elements should not be greater than $\lambda / 10(\lambda$ : wavelength). Otherwise, parts of the seismic waves will be filtered.

According to Table 2, the basic configuration of pile was selected as follows: diameter $(D)=1 \mathrm{~m}$, length $(L)=21$, length above ground surface (free length $)=1 \mathrm{~m}$, pile wall thickness $=1 \mathrm{~cm}$, and modulus of elasticity $=30 \mathrm{GPa}$. Pile head was pinned and its material behavior selected to be linear elastic. Pile elements were connected to the surrounding soil nodes by very stiff beam column elements. According to a study by Uncuoglu and Laman [40], the pilesoil interface elements have low strengths and get to yielding immediately during earthquake. In other words, the interface elements do not have much effects on the pile-soil response in this situation. This concept was also validated by authors in the first steps of the current research. Superstructure mass $(M)$ at the top of the pile was primarily selected equal to 20 tons. For sensitivity analyses, many of these parameters were altered later.

Input motions in the form of sine wave with duration of $10 \mathrm{sec}$ were applied to the base of the model. Four different frequencies $(f)$, namely $1,2,5$, and $10 \mathrm{~Hz}$, were chosen for the loading wave, and the wave strength was selected to be equal to PGA $=0.15$ $\mathrm{g}$ and $0.25 \mathrm{~g}$. Due to the similarity of results for pairs 


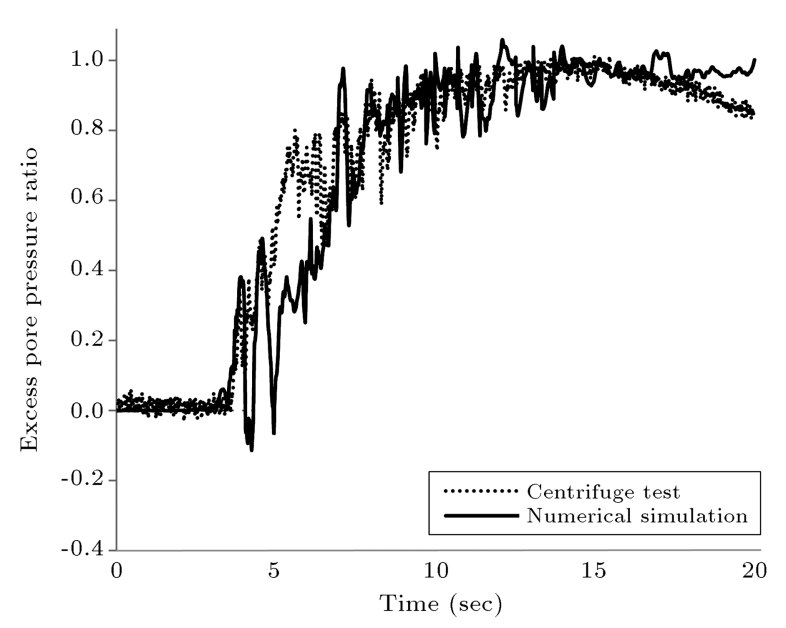

Figure 7. Time history of $R_{u}$ at $z=1 \mathrm{~m}$ and $x=6.6 \mathrm{~m}$ from pile wall.

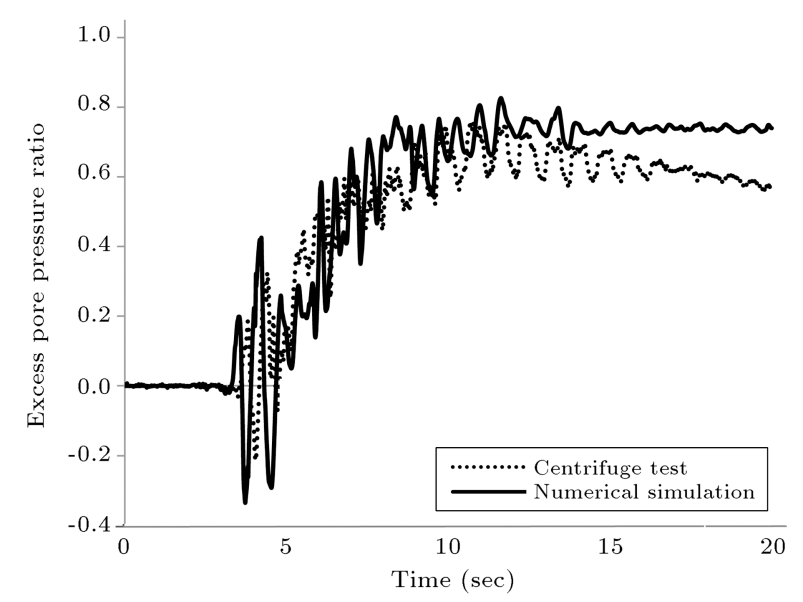

Figure 8. Time history of $R_{u}$ at $z=4.5 \mathrm{~m}$ and $x=0.005 \mathrm{~m}$ from pile wall.

$f=1,2 \mathrm{~Hz}$ and $f=5,10 \mathrm{~Hz}$, most of the comparisons are based on the results with $f=2$ and $5 \mathrm{~Hz}$.

To verify the suitability of model in reproducing logical results, a centrifuge test carried out by Wilson [2], named Csp3 for Event J, was selected; the responses of excess pore pressure, superstructure acceleration, and bending moment of pile were compared with those of the physical model. As shown in Figures 7 to 12 , the results of the current FEM model are in good agreement with those of centrifuge tests in terms of excess pore pressure ratio, pile bending moments and accelerations. Therefore, the model is capable of appropriately predicting soil and pile responses under dynamic loading of earthquakes.

\section{Simulation and results}

Soil and pile responses were discussed in 3 sections. In the first section, generation of excess pore water pressure and variations in its ratio $\left(R_{u}\right)$ was investigated for $\mathrm{PGA}=0.15 \mathrm{~g}$. In the second section, displacements

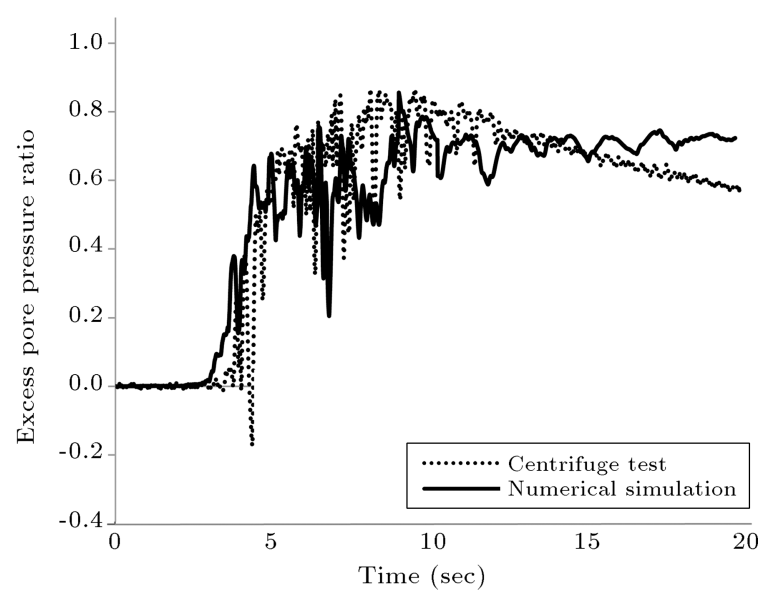

Figure 9. Time history of $R_{u}$ at $z=4.5 \mathrm{~m}$ and $x=9.8 \mathrm{~m}$ from pile wall.

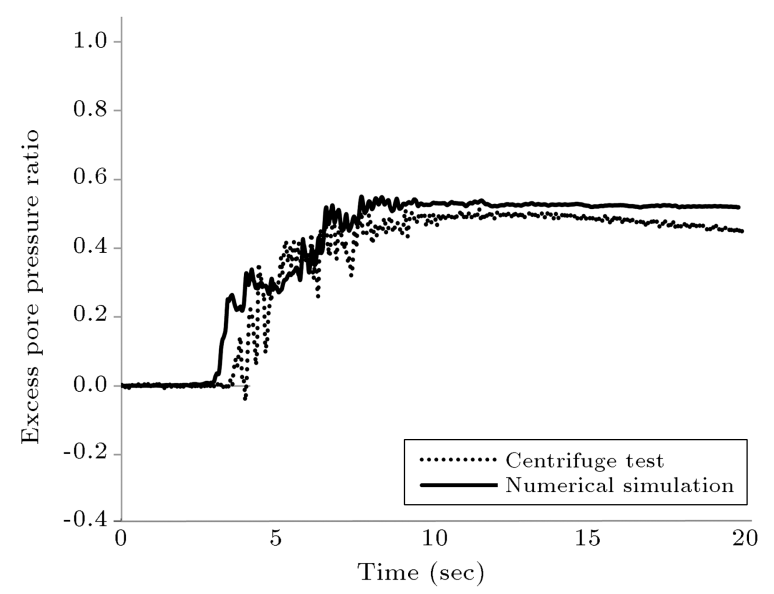

Figure 10. Time history of $R_{u}$ at $z=21 \mathrm{~m}$ and $x=5 \mathrm{~m}$ from pile wall.

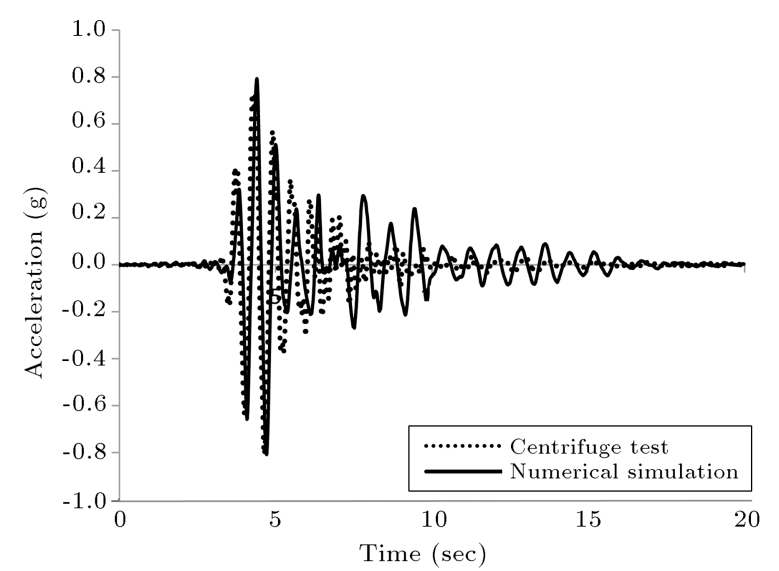

Figure 11. Time history of acceleration of superstructure.

of pile were studied, and in the last section, bending moments of pile were investigated.

\subsection{Excess pore water pressure}

$R_{u}$ is a practical parameter for studying liquefaction. It is defined as the ratio of excess pore water pressure 


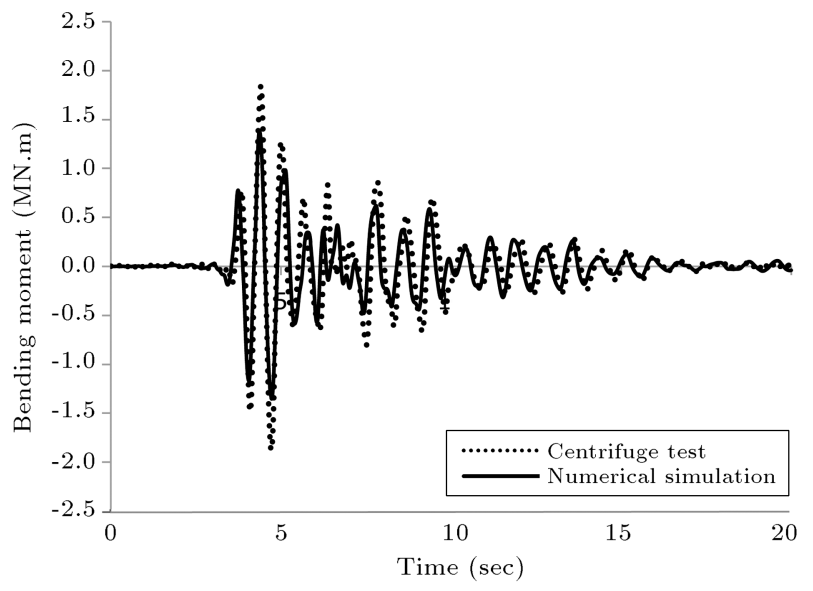

Figure 12. Time history of pile bending-moment response at $z=4 \mathrm{~m}$ depth from ground surface.

to the initial effective vertical stress $\left(R_{u}=\Delta u / \sigma_{0 v}^{\prime}\right)$. When $R_{u}$ becomes equal to 1 , the soil has liquefied completely and would not exhibit any further shear strength. To investigate the variations of PWP at different depths in the soil, 4 points were considered. Two of the points located at $z=5 \mathrm{~m}$ and $z=8 \mathrm{~m}$ were used as representative for the behavior of the soil with low relative density, and the other two points at $z=16 \mathrm{~m}$ and $z=27 \mathrm{~m}$ represent the denser stratum. The points have been chosen so as to capture the values of PWP and their variations at: (a) one point at loose sand stratum, (b) coincidence region or interface area of the loose and dense layers, (c) near the end of the pile, (d) depth under pile toe, respectively. The mentioned points are illustrated in Figure 13.

For evaluating the effect of different parameters on the trend of variations in PWP and its distribution through soil layers, different figures were produced and discussed. In general, any result regarding the changes in PWP can be attributed to the variations in shear strength of the soil during liquefaction. Responses of an embedded pile in the ground could be predicted according to the figures noted above. In this study, the focus was placed on the comparative investigation and interpretation of the performance of soil and pile

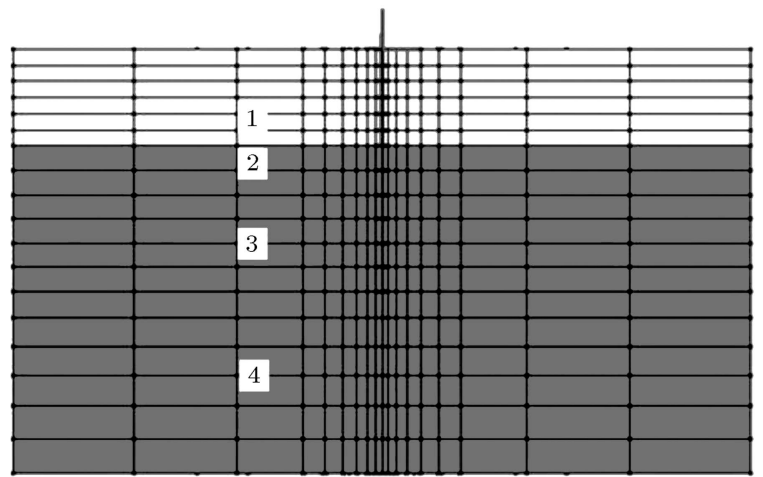

Figure 13. Points of calculating pore water pressure.

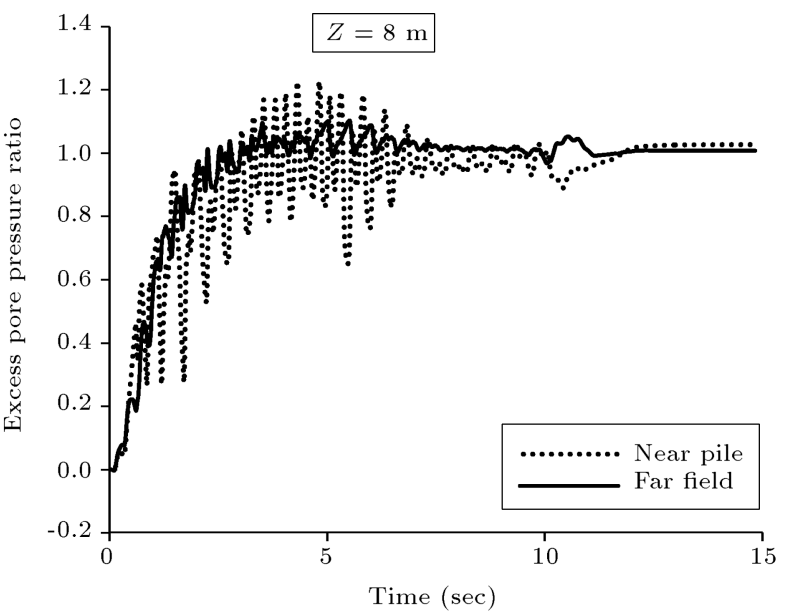

Figure 14. Comparison of $R_{u}$ made for far-field and near-filed cases at $z=8 \mathrm{~m}$.

system in Cases I and II. By comparing the mentioned cases, a general insight into the effect of clay cover on the behavior of system with different configurations would be achievable. It may be interesting to initially compare soil responses for far-field and near-field conditions. Far-field responses are very analogous to the responses in the cases without a pile. According to Figure 14, it is clear that the presence of pile has caused fluctuations in PWP. In contrast, such oscillations do not exist in the far-field case.

Figures 15 to 18 show that $R_{u}$ generally tends to decrease with an increase in depth. This trend can be explained based on the dissimilarity of soil's density (and stiffness, of course) for the two distinct layers. For the upper section of the model, $D_{r}$ is lower resulting in larger oscillations of soil grains. As a result, the soil's structure tends to densify and pore water is forced to drain out of the soil voids. Pressure of pore water increases during this event.

Furthermore, the frequency of base excitation does not affect the liquefaction process in the upper layer of the system ( $\left.T h=8 \mathrm{~m}, D_{r}=40 \%\right)$ based on Figures 15 to 18 . According to this fact, liquefaction can occur in every part of the soil from ground surface up to $z=8 \mathrm{~m}$ for all cases. Therefore, occurrence of liquefaction for the upper layer (low relative density) seems to be irrelevant to the frequency of base motion.

For excitations with $f=5 \mathrm{~Hz}$ and $f=10 \mathrm{~Hz}$, $R_{u}$ does not change significantly at deeper levels (e.g. $z=27 \mathrm{~m}$ ). However, $R_{u}$ reached an approximate value of 0.5 at this depth for excitation with $f=2 \mathrm{~Hz}$. This response was also observed and reported by Yao et al. [4]. They concluded that with increasing the frequency of the base motion, amplitude of vibration of soil grains decreases.

By running an eigenvalue analysis, it was determined that natural frequency of the described soil and pile system $\left(f_{n}\right)$ is equal to $2 \mathrm{~Hz}$. Based on 


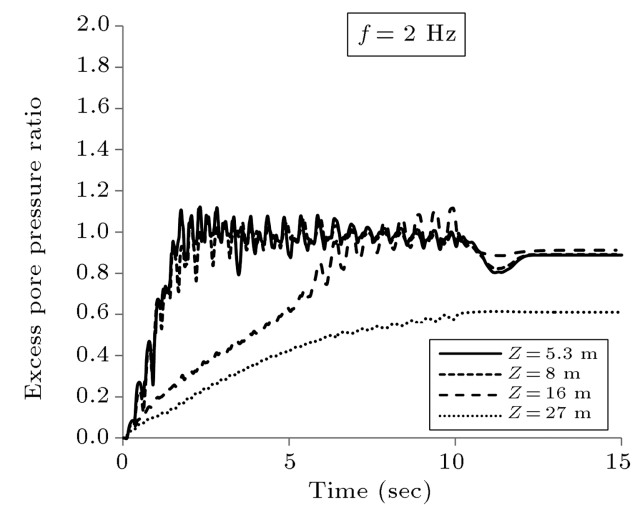

(a)

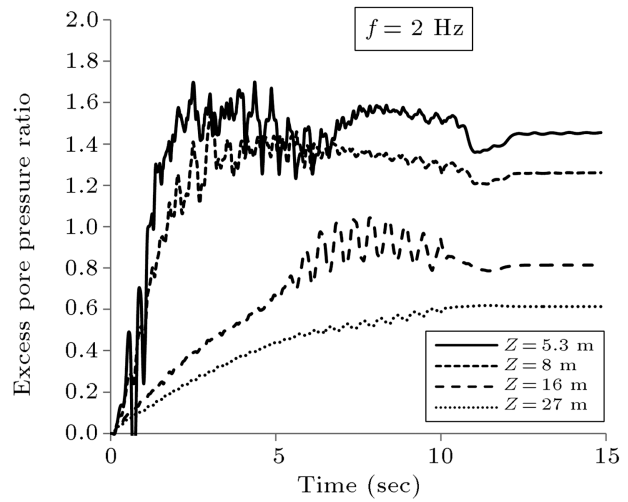

(b)

Figure 15. Time history of $R_{u}$ at $z=5.3,8,16$, and $27 \mathrm{~m}$ and $x=12 \mathrm{~m}$ from pile for base excitation with $f=2 \mathrm{~Hz}$ for (a) Case I and (b) Case II.

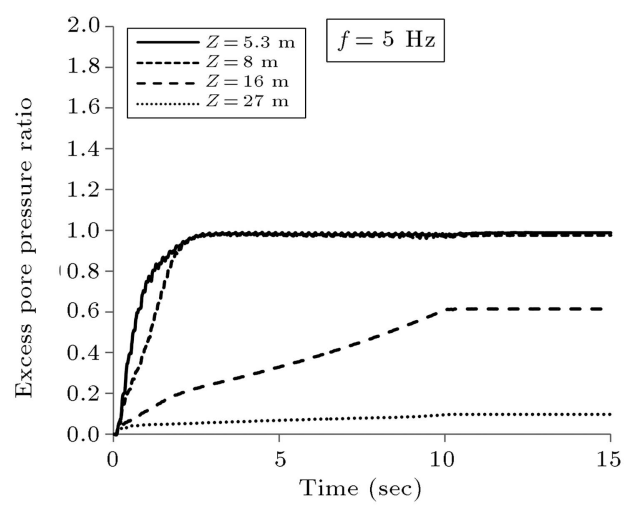

(a)

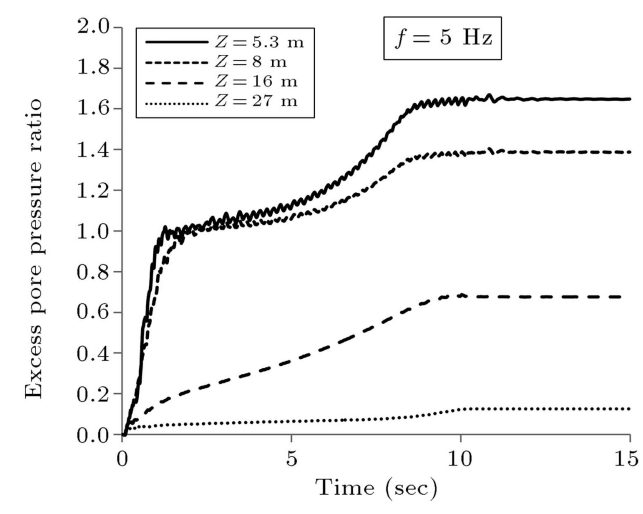

(b)

Figure 16. Time history of $R_{u}$ at $z=5.3,8,16$, and $27 \mathrm{~m}$ and $x=12 \mathrm{~m}$ from pile for base excitation with $f=5 \mathrm{~Hz}$ for (a) Case I and (b) Case II.

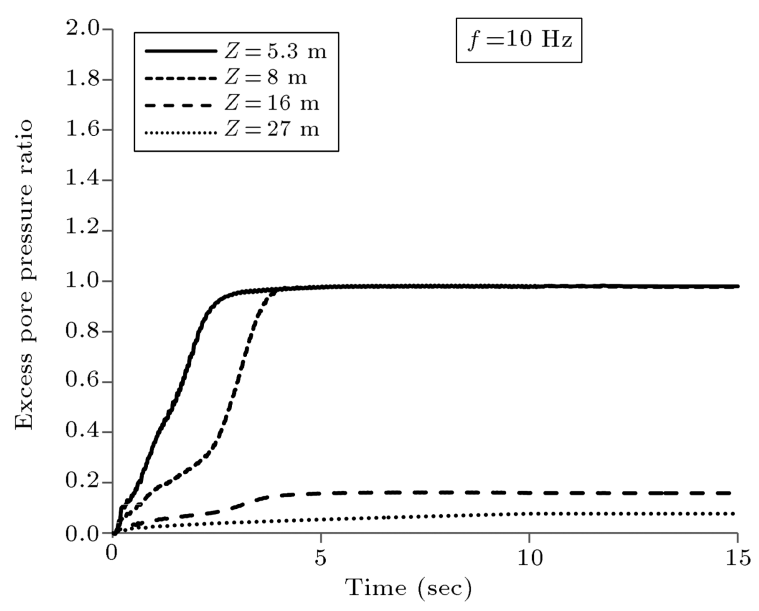

Figure 17. Time history of $R_{u}$ at $z=5.3,8,16$, and $27 \mathrm{~m}$ and $x=12 \mathrm{~m}$ from pile for base excitation with $f=10 \mathrm{~Hz}$ for Case I.

the conclusion extracted from this fact, the previous paragraph, and supposing other influencing parameters to remain unchanged, one can deduce that $R_{u}$ has a stronger tendency to build up for base excitations with a frequency that is equal to or less than the natural

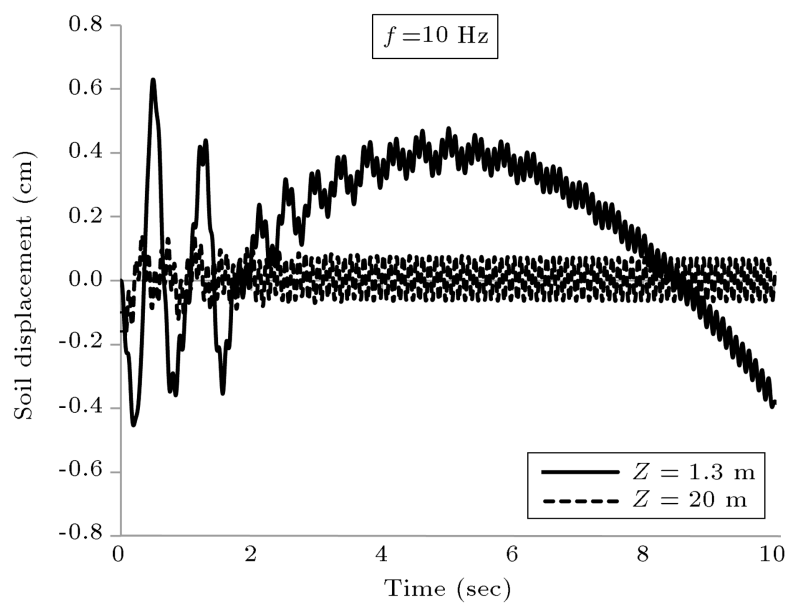

Figure 18. Time history of soil displacement at $z=1.3$ and $20 \mathrm{~m}$ and $x=11 \mathrm{~m}$ from pile for base excitation with $f=10 \mathrm{~Hz}$ for Case I.

frequency of the system. Therefore, to avoid probable general collapse of pile and its supported structure, it is recommended to select a longer pile and drive it to a deeper level into the ground.

Due to higher pressure on soil elements exerted 
from nearby elements at deeper points, soil particles are restrained to oscillate with an imposed frequency. Hence, they can just vibrate with their own natural frequency, and as a result, the amplitude of vibration tends to reduce. This fact is derived from Figure 18. It illustrates that prior to soil liquefaction, amplitude of vibrations at $z=1.3 \mathrm{~m}$ is approximately 4 times larger than its amount at $z=20 \mathrm{~m}$.

Based on Figure 13, soil displacement reaches a maximum value followed by a gradual decrease at points close to ground surface. The reason can be attributed to momentum of soil mass and the direction of velocity vector for soil elements at the moment of the initiation of liquefaction. Different layers of soil are likely to move in different directions according to their velocity vectors and their directions at the beginning of liquefaction. For instance, by considering Figure 17, it is clear that liquefaction takes place at $t=2 \mathrm{sec}$ for $z=5.3 \mathrm{~m}$. The direction of soil displacement for the same time is positive based on Figure 18. Therefore, the whole soil mass placed above this level also starts to move in the positive direction at $t=2 \mathrm{sec}$. By utilizing the same logic for $t=5 \mathrm{sec}$, there exists a point located at deeper levels that has started to liquefy, while the soil mass had a negative moving direction, and as a result, the resultant direction of soil displacement observed at ground surface changed. This behavior has been observed somehow in the study of Rahmani and Pak [23], too.

Another point obtained from Figures 15 to 18 is that the rate of increase in $R_{u}$ is larger for loadings with lower frequencies for a definite depth (for instance $z=8 \mathrm{~m}$ ). In other words, with an increase in the frequency of the base excitation, it takes longer for the soil to liquefy. Therefore, loadings with higher frequencies take longer to trigger the liquefaction in soil.

By comparing Figure 15 with Figure 16 for each of the cases, one can discover that $R_{u}$ increases to a higher bound in comparison to Case I for the region just below the clay cover; therefore, liquefaction happens more intensely for Case II. A physical explanation for this phenomenon can be provided by the low permeability of clay cover over granular layer. During the application of earthquake loading to soil, pore water drains from deeper point towards the ground surface. The cohesive material covering granular stratum acts as an impermeable layer against the stream of pore water and avoids rapid drainage of water. Therefore, PWP increases just below the deposit of clay. The presence of such cohesive cover has also resulted in a shorter period of time required for liquefaction. In the study of Yang and Elgamal [29], an analogous phenomenon is observed. They investigated the effect of placement of a thin layer of clay over a sand bed. It was concluded that the sand bed loses its effective confinement due to low permeability of clay. Drainage of water toward ground surface was blocked and PWP could not drop instantly; so, the sand bed turned into water from surface of the ground to a depth of few meters into it. According to the discussed facts, when a typical layer of very soft or normal clay is placed over a sand stratum and soil is exposed to the base excitation, it liquefies and loses shear strength rapidly. Compared with a single layer of sand, liquefaction can also penetrate into deeper regions of the ground. This will consequently affect the embedded structures such as piles.

It is interesting to deliberate on the number of loading cycles needed to initiate a complete liquefaction. According to Figure 15(a), for Case I, it can be observed that soil becomes completely liquefied after 4 cycles of loading, and based on Figure 15(b), it starts only after 2 cycles for Case II. Therefore, a complete liquefaction has occurred only after a few cycles of loading. Cubrinovski et al. [41] found that for a base excitation with $f=2 \mathrm{~Hz}$ and $\mathrm{PGA}=$ $0.22 \mathrm{~g}$, soil liquefies completely in 4 seconds and after 6 cycles of loading. However, it should be noticed that in their study, acceleration time history has a gradual increase from zero to a maximum value. In other words, the vibration amplitude is almost equal to zero until $t=1 \mathrm{sec}$, and it reaches $0.15 \mathrm{~g}$ at $t=4 \mathrm{sec}$. In other words, in the first 4 seconds, 6 cycles of loading with amplitude less than $0.15 \mathrm{~g}$ were applied to their model. Meanwhile, sand had a relative density equal to $50 \%$ in their research, which is more than that of the current research. To summarize the above discussion, it is reasonable that for Case I with $\mathrm{PGA}=0.15 \mathrm{~g}$, soil has started to liquefy after 4 or 5 cycles. For Case II and knowing about the governing phenomenon discussed earlier with regard to role of clay deposit, it could also be rational that complete liquefaction initiates after 2 cycles of loading according to Figure $15(\mathrm{~b})$.

Figures 19 and 20 show that $R_{u}$ increases with time and decreases generally with an increase in depth. The point here is the recurrence of the graphs, which starts from $z=8 \mathrm{~m}$ and turning back nearly at $z=12 \mathrm{~m}$. Therefore, $R_{u}$ has not only reduced at these depths, but also it has reversed. $D_{r}$ has changed from $40 \%$ to $70 \%$ at $z=8 \mathrm{~m}$, and therefore, some sort of discontinuity or separation is inevitable at this region of ground. After the first cycles of loading and beginning of liquefaction in the upper parts of ground, this liquefied upper layer flows over its supporting bed, inducing a higher shear strength at the region of separation. This means that the condition of soil stress at this region is located somewhere between phase transition line and failure line, and soil dilates because of shearing between the two adjacent regions. At this state, suction happens in the voids of the soil 


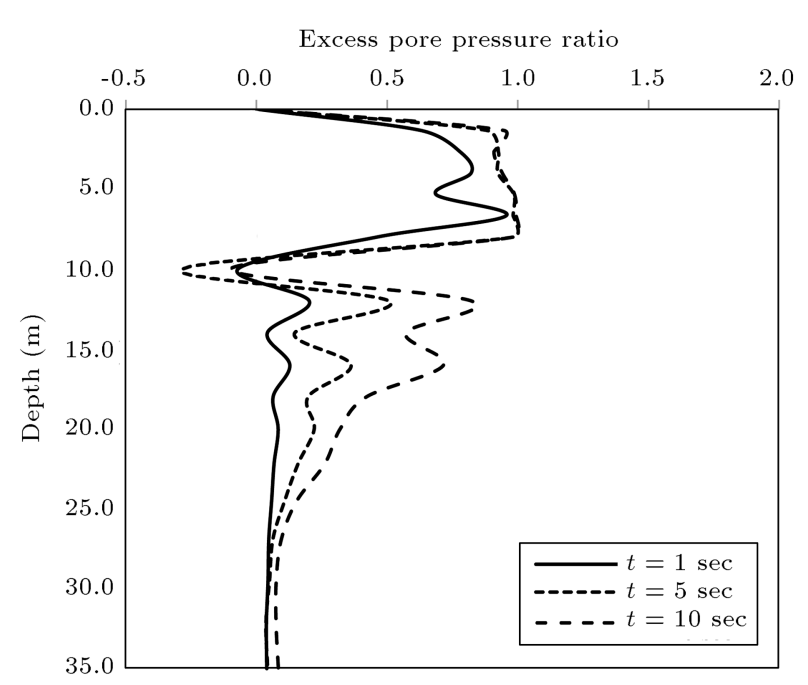

Figure 19. Distribution of $R_{u}$ in depth for base excitation with $f=5 \mathrm{~Hz}$, at $t=1,5$, and $10 \mathrm{sec}$ for Case I.

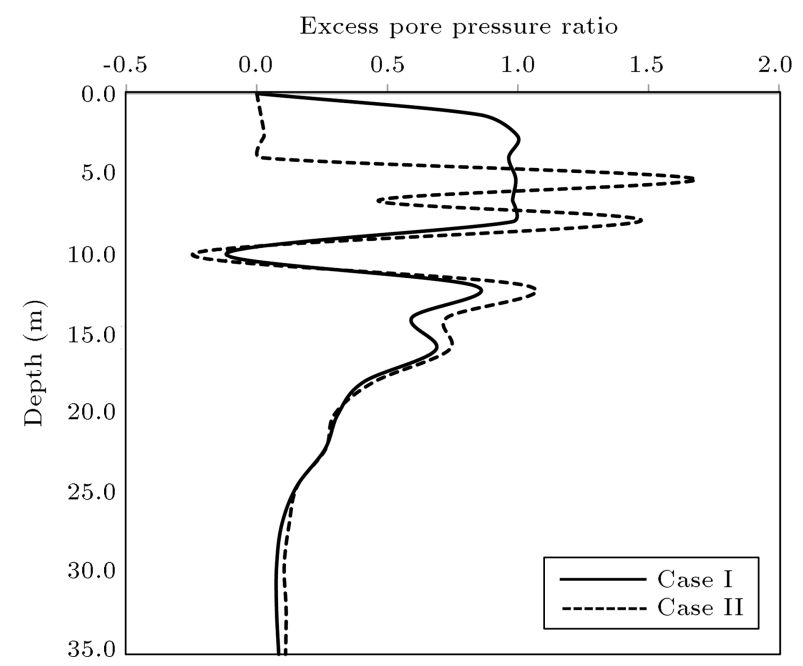

Figure 20. Comparison of the distribution of $R_{u}$ for Cases I and II at $t=10 \mathrm{sec}$.

skeleton and PWP decreases, causing a slight increase in soil's strength. According to de Groot et al. [42], when mean shear stress is large enough and sand is not very loose, mean PWP becomes negative, and effective stress increases similar to the state of soil described here. For a homogenous soil layer that has no variation in material properties with respect to depth, such behavior is not expected and $R_{u}$ will decrease with depth monotonously.

For Case II and according to Figure 20, $R_{u}$ increases more intensively under clay deposit. In this case, it is observed that in addition to the decrease of $R_{u}$ between $z=8 \mathrm{~m}$ and $z=12 \mathrm{~m}$, a decrease in $R_{u}$ is also observed locally at $z=7 \mathrm{~m}$. However, this reduction is not so severe and $R_{u}$ does not become 0 or negative as it only comes to nearly 0.5 . So, in this region, no significant change in soil shear strength is probably expected.

\subsection{Lateral displacement of soil and pile} 5.2.1. Effect of the frequency of base excitation Time history of soil's lateral displacement at $x=5.5 \mathrm{~m}$ from pile is shown in Figures 21 and 22 for different frequencies. Amplitude of vibrations reduces with an increase in the frequency of excitation for both Cases I and II. This reduction is in agreement with variations of $R_{u}$ discussed in Section 5.1.

In both cases, amplitude of oscillations of soil particles has a larger value prior to liquefaction compared to its value after liquefaction. The reason lies in the fact that shear wave traveling from deep parts of ground through soil medium is damped somewhat after liquefaction, and amplitude of soil vibration decreases, consequently. In addition, Haeri et al. [9] and Lu et al. [43] reported this phenomenon in their research.

By comparing Figures 21 and 22, it is apparent

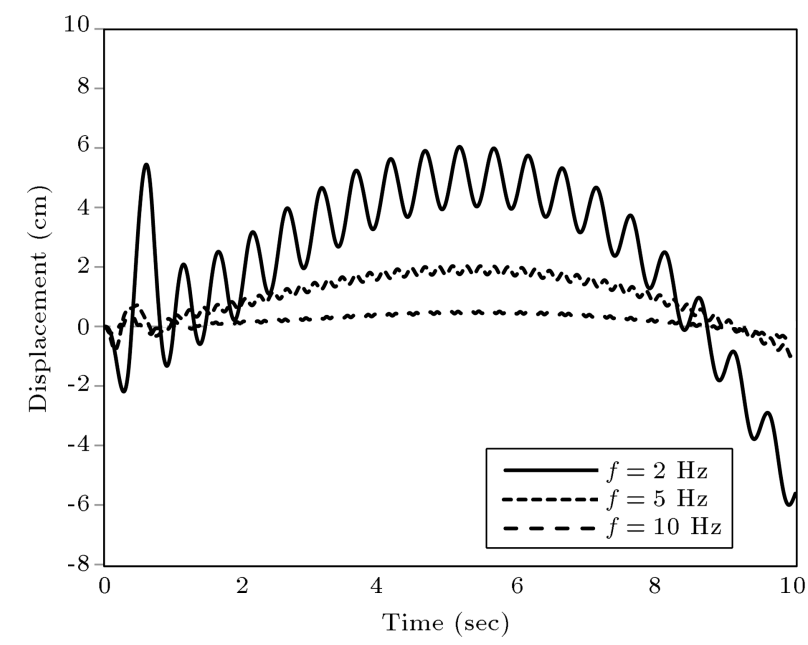

Figure 21. Time history of soil displacement at ground surface far from pile for base excitation with different frequencies for Case I.

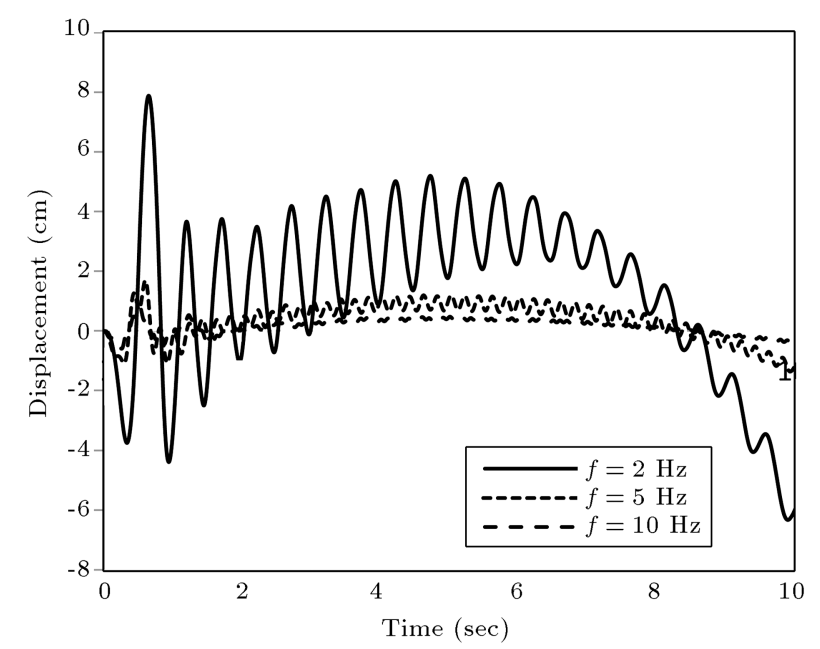

Figure 22. Time history of soil displacement at ground surface at a far distance from pile for base excitation with different frequencies for Case II. 
that soil experiences higher damping for Case II relative to Case I. As discussed in the previous sections, the presence of clay layer causes the soil to liquefy faster with more intensity, which is consistent with the increase in soil damping.

\subsubsection{Maximum displacement of pile}

According to Figures 23 to 26, the increasing frequency of base excitation causes a reduction in pile lateral displacement. By comparing the mentioned figures, it is perceivable that the pile displacement limits its upper portions with an increase in excitation frequency. The reason for such behavior is the restriction of

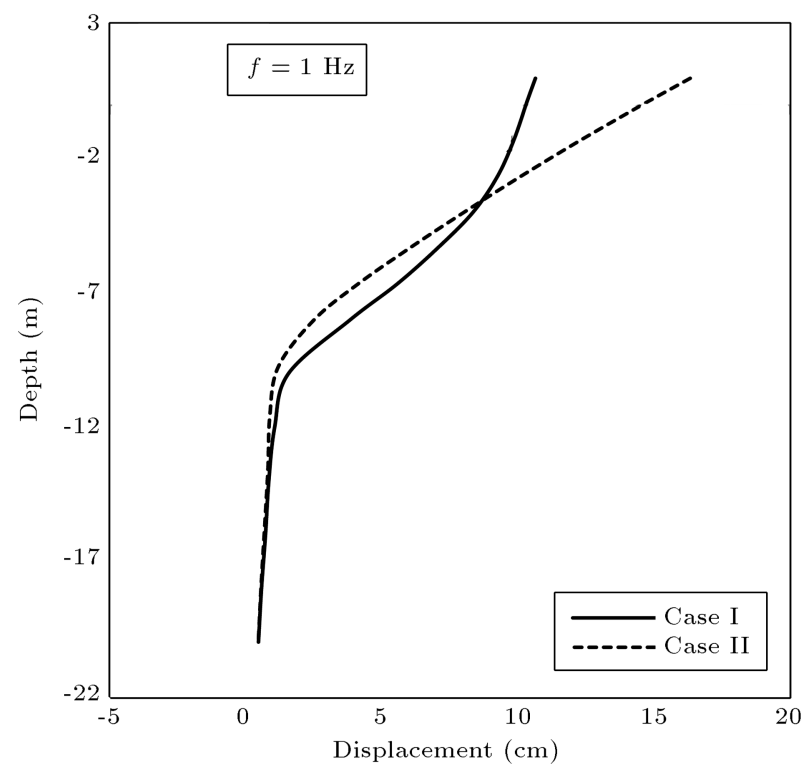

Figure 23. Comparison of maximum pile displacement for $f=1 \mathrm{~Hz}$ for Cases I and II.

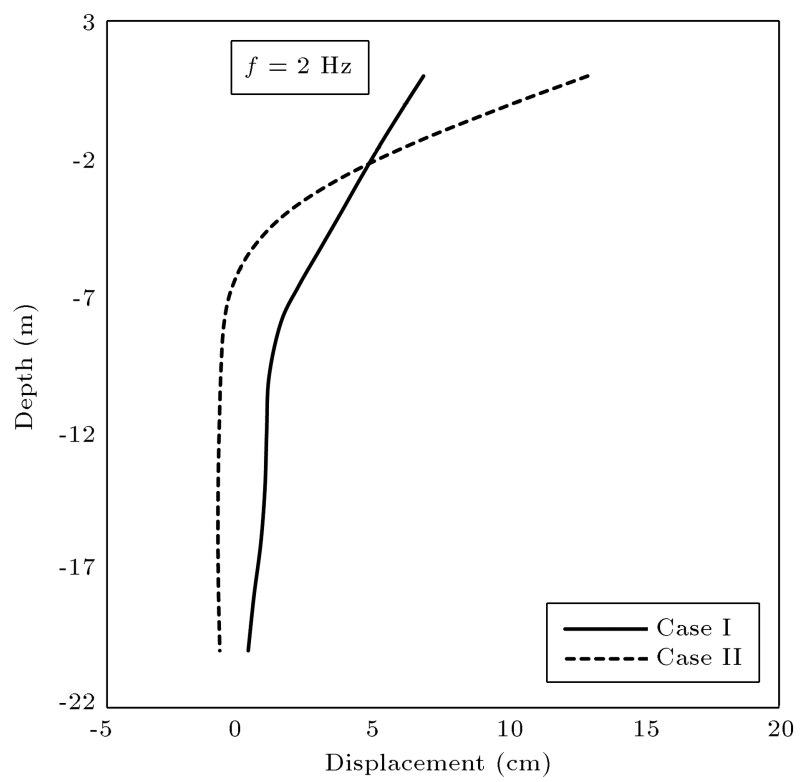

Figure 24. Comparison of maximum pile displacement for $f=2 \mathrm{~Hz}$ for Cases I and II. soil liquefaction to its upper layers with a growth in frequency. In this condition, maximum lateral displacement of pile for an excitation with $f=1 \mathrm{~Hz}$ is approximately 15 times greater compared to $f=10 \mathrm{~Hz}$.

It is also apparent that for excitations with $f=$ $1 \mathrm{~Hz}$ and $f=2 \mathrm{~Hz}$ in Case II, maximum pile displacement is up to $50 \%$ larger than its maximum displacement in Case I. For Case II, this maximum value occurred before liquefaction, and its reason was discussed in the previous sections.

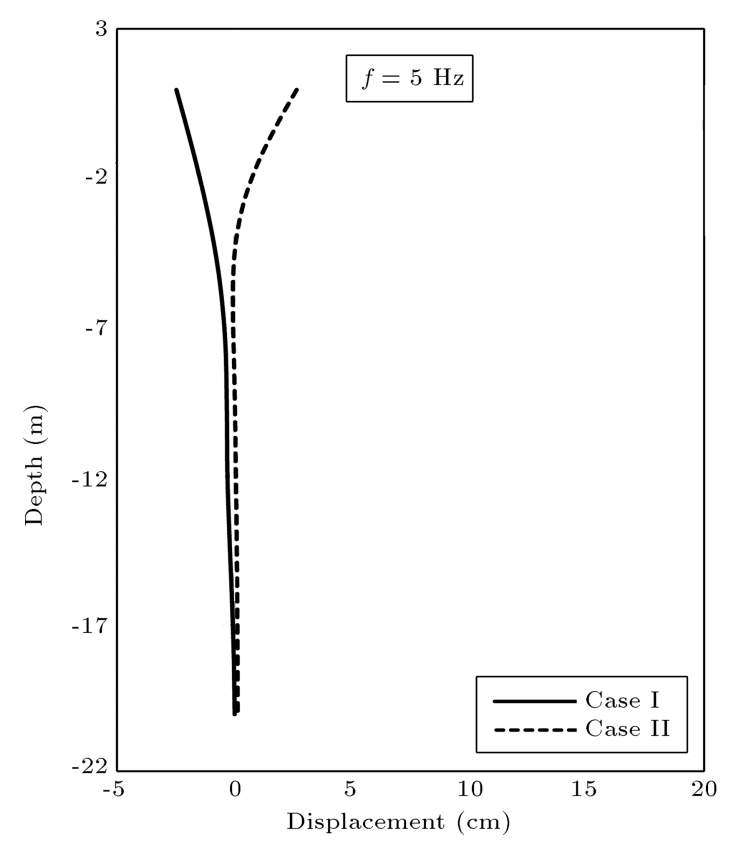

Figure 25. Comparison of maximum pile displacement at $f=5 \mathrm{~Hz}$ for Cases I and II.

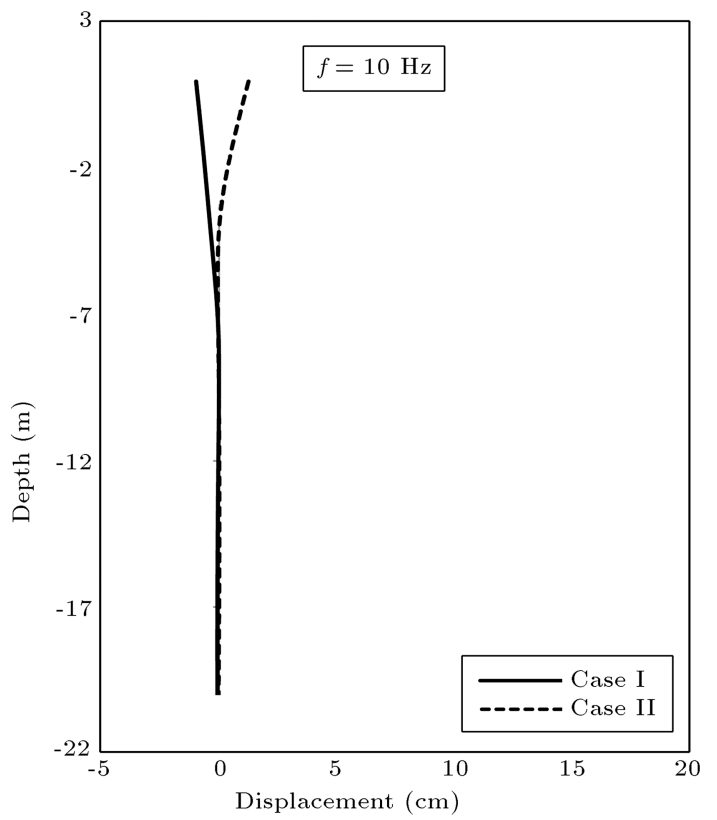

Figure 26. Comparison of maximum pile displacement at $f=10 \mathrm{~Hz}$ for Cases I and II. 


\subsubsection{Effect of pile length on its maximum displacement}

Based on Figure 27, changing pile length without changing its diameter has only limited influence on maximum displacement of pile head, which is in agreement with the results of Rahmani and Pak [23].

After the end of base excitation following the termination of imposed inertial forces of structural mass, the shortest pile $(L / D=15)$ has experienced large displacements at its toe. This occurs since a large proportion of pile length is embedded inside the liquefied region. Liquefied soil starts to flow and applies a large kinematic force to pile toe, which in turn causes larger movement in it. If superstructure mass is large enough, this will likely lead to total instability in the structure. Comparing $L / D=20$ with $L / D=25$, it is concluded that an increase in pile length from 20 to $25 \mathrm{~m}$ does not have significant impact on its displacement.

\subsubsection{Effect of pile diameter on its maximum displacement}

Figure 28 shows the effect of pile diameter on its maximum displacement. In Case I, the reason for the difference in displacement patterns in piles with $D=$ 1.2 and $1.5 \mathrm{~m}$ with other piles can be attributed to their larger side surface, which resists against kinematic forces. For piles with these two diameters, maximum displacement happens after deeper parts of soils are liquefied. Hence, larger forces are applied from soil to pile due to larger side resisting area of pile against

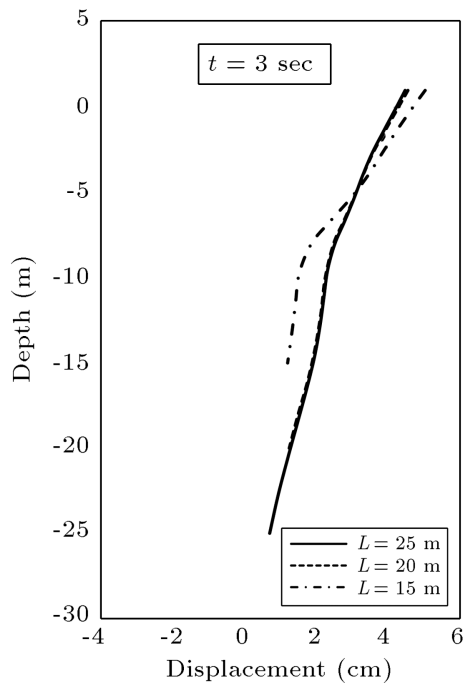

(a)

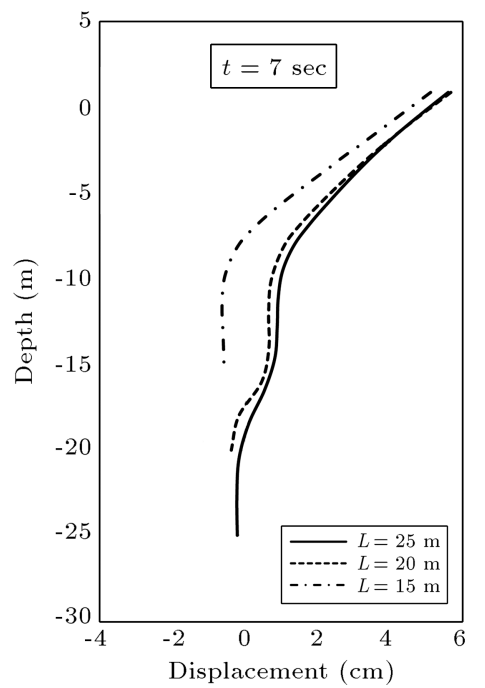

(b)

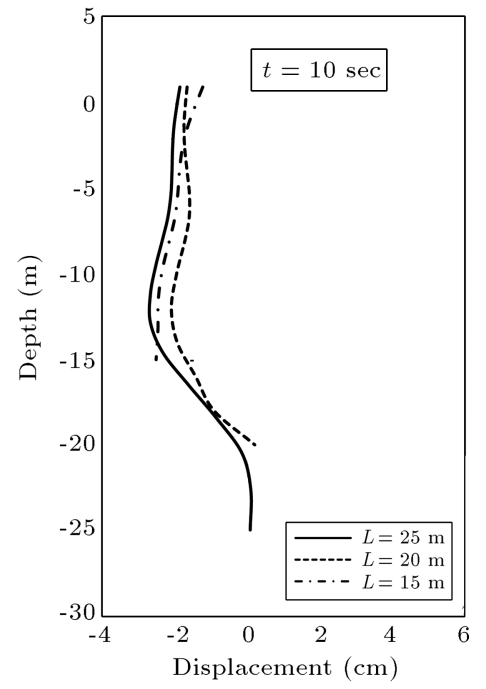

(c)

Figure 27. Comparison of lateral profile of pile displacement at $t=3$, 7, and $10 \mathrm{sec}$ for different pile lengths.

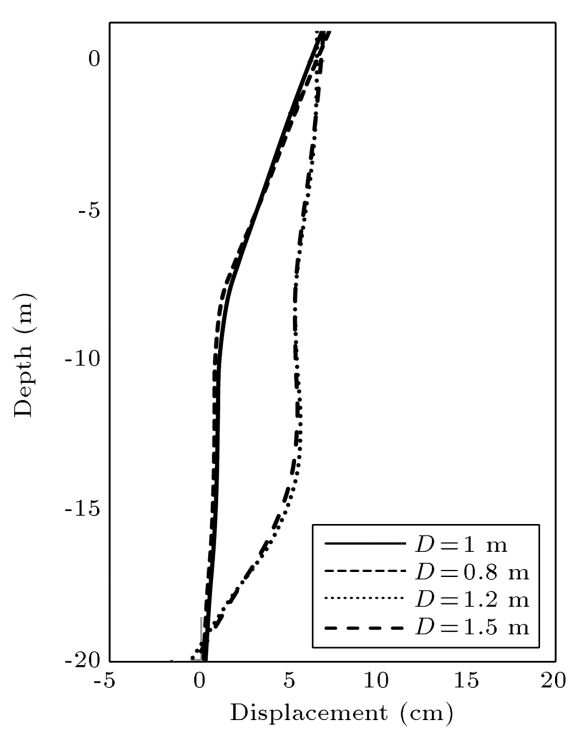

(a)

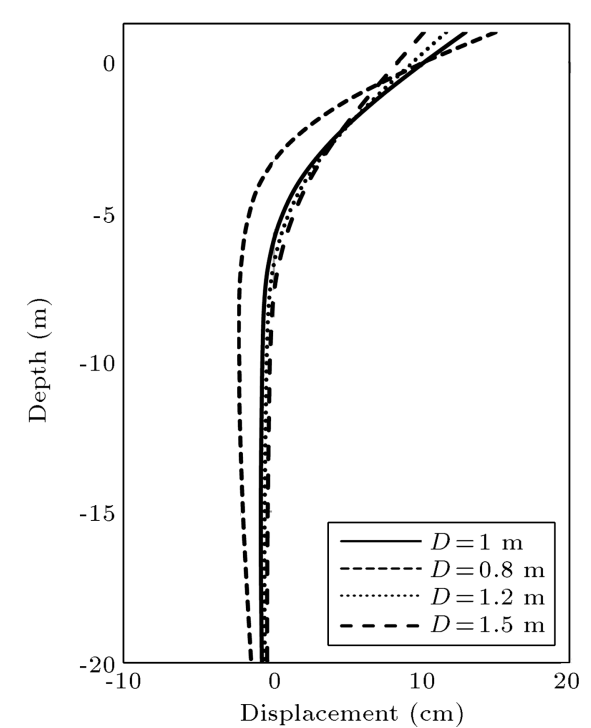

(b)

Figure 28. Maximum pile lateral displacement in depth for piles with different diameters for (a) Case I and (b) Case II. 


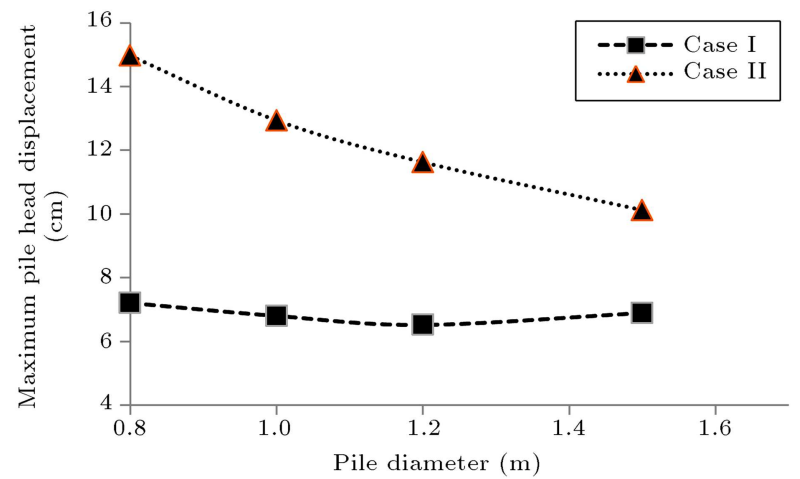

Figure 29. Comparison of maximum lateral displacement of pile head with respect to pile diameter for Case I after liquefaction and for Case II before liquefaction.

kinematic forces. Actually, pile is so rigid that does not bend too much itself. However, kinematic pressure makes it displace laterally. Displacement of pile head also increases accordingly. For Case II, the same event happens. However, the difference in the patterns is not evident, because maximum translation in pile occurs before liquefaction.

Depicting the maximum pile head displacements against their diameter in Figure 29 helps understand better the issue discussed in the previous paragraph. In Case II, maximum displacements of pile reduce with an increase in piles diameter, since these peak values are related to the pre-liquefaction state. This is sensible due to the increase in piles stiffness. For Case I, a slight decrease in maximum displacement of pile head is observed when diameter of pile is increased up to $D=1.2 \mathrm{~m}$. Although pile gets stiffer against bending with the increase in its diameter, kinematic forces acting against pile tend to increase based on the discussions in the previous paragraph. Consequently, pile's displacement increases due to the increase in its lateral surface resisting against flowing soil mass after liquefaction.

\subsubsection{Effect of pile free length on its maximum displacement}

If superstructure height from surface is altered or in other words, if pile free length is changed, pile displacements at ground surface do not considerably get influenced due to great stiffness of piles as it can be concluded from Figure 30 .

\subsection{Bending moment of pile}

For investigating bending moments of pile with respect to depth, their time history diagram at $z=8 \mathrm{~m}$ and $z=16 \mathrm{~m}$ was selected as representative points for the peak value of bending moments, shown in Figure 31 for Case I with $f=2 \mathrm{~Hz}$. Amplitude of bending moment and its maximum value decreases with respect to time for $z=8 \mathrm{~m}$, while a contrary trend is observed for $z=16 \mathrm{~m}$. In other words, peak amount of

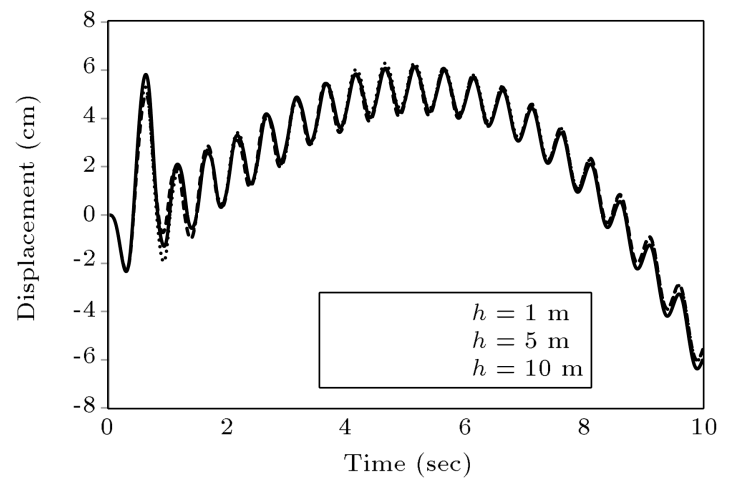

Figure 30. Time history of pile displacements at ground surface for piles with different free lengths.

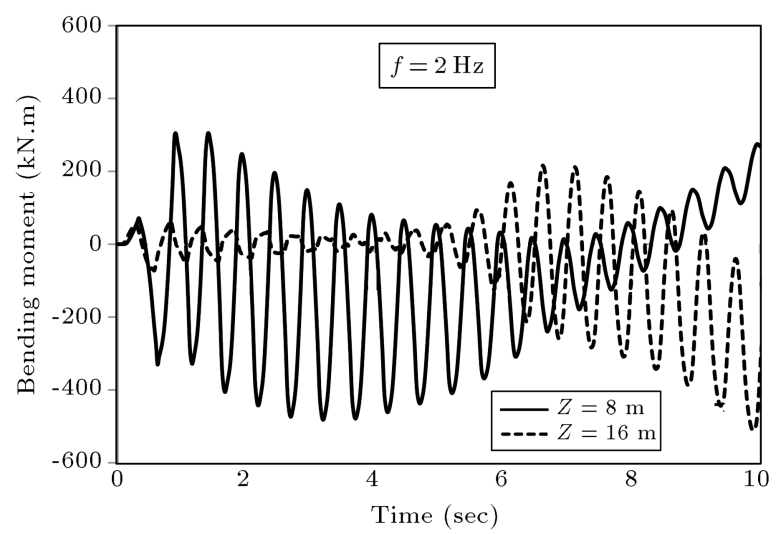

Figure 31. Time history of pile bending moment at depths 8 and $16 \mathrm{~m}$ under base excitation with $f=2 \mathrm{~Hz}$ for Case I.

bending moment occurs in different times for various locations of pile length. The reason for such a manner is originated from the change in subgrade reaction factor, ground displacement, and superstructure acceleration response, according to Yao et al. [4].

\subsubsection{Effect of clay layer and its thickness}

According to the discussions in the previous sections and the result obtained for variations of $R_{u}$ in Cases I and II, it can be predicted that the presence of a layer of soft clay with a variety of thicknesses could possibly affect maximum value of bending moments. Figures 32 to 34 should be noticed for making a clearer observation.

For Case I and due to a longer period of time needed for liquefaction to penetrate deeper into the ground, pile Maximum Bending Moment (MBM) occurs at $z=18 \mathrm{~m}$ in $t=10 \mathrm{~s}$. According to Tokimatsu et al. [5], bending moment of piles subsequent to liquefaction is larger than its value prior to liquefaction. This probably happens due to the increase in soil shear strength produced by kinematic forces. Typically, shear forces are smaller than inertial forces prior to liquefaction; they become equal to or larger than that after liquefaction. Meanwhile, peak value of bending 


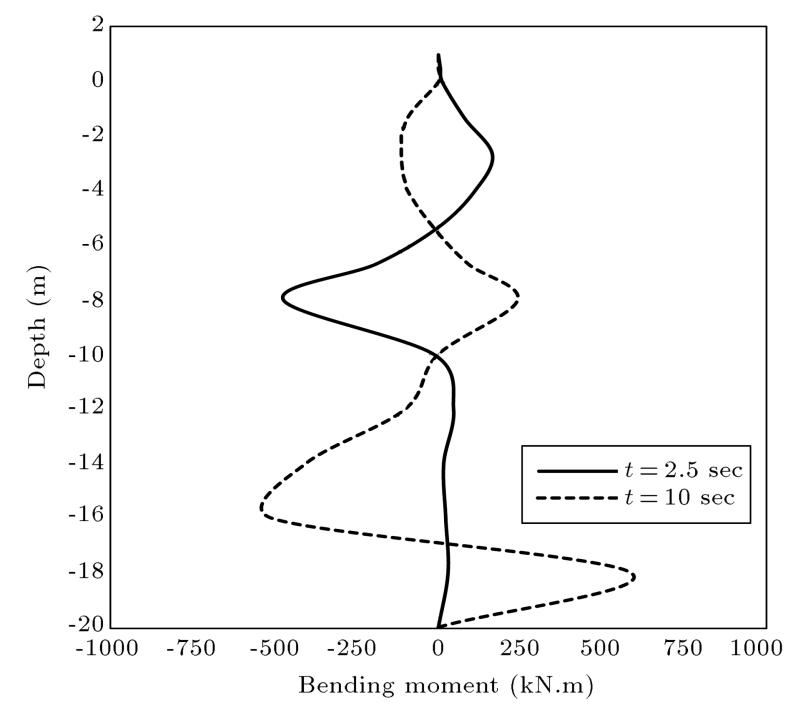

Figure 32. Maximum bending moments in pile, $f=2 \mathrm{~Hz}$, Case I.

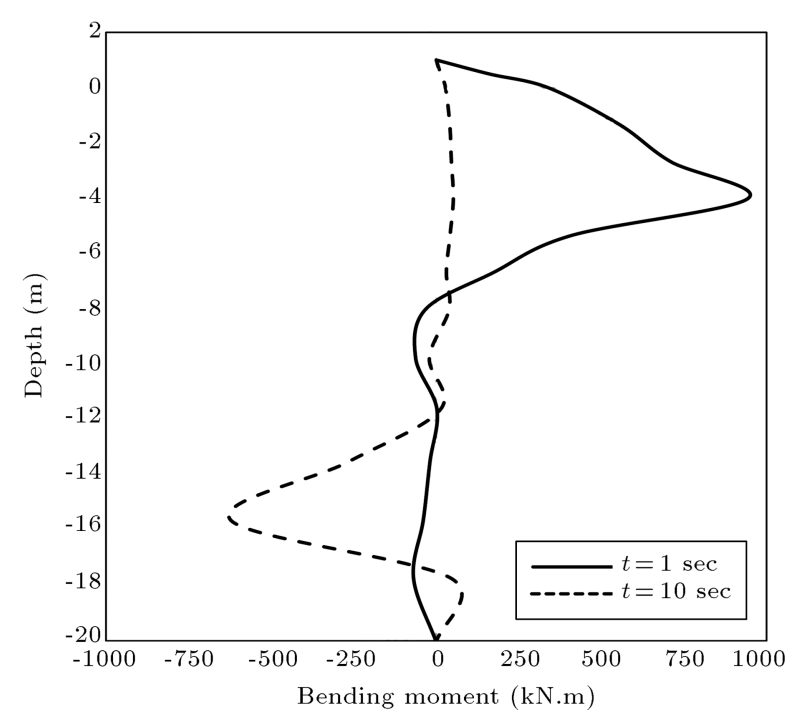

Figure 33. Maximum bending moments in pile, $f=2 \mathrm{~Hz}$, Case II with $T h=4 \mathrm{~m}$.

moment occurs once soil displacement and inertial forces are great. Period of liquefied soil is always greater than the period of superstructure; so, the effect of pile displacement and inertial forces fall in the same phase, and thus, pile bending moments increase [5].

Transfer of the location of MBM of pile to deeper stratums is another interesting issue to discuss. Nearly for all cases, MBMs happen after complete liquefaction and in upper parts of ground $(z=16 \mathrm{~m}$ to $z=18 \mathrm{~m})$. For Case II with clay cover of $T h=4$, the situation seems to be different. According to Figure 33, MBM in pile occurred at $z=4 \mathrm{~m}$ before liquefaction. It can be concluded that for this case, MBM occurs due to high softness of the clay layer rather than liquefaction. However, when the thickness of clay layer is increased to $T h=8 \mathrm{~m}$, MBM takes place at $z=16 \mathrm{~m}$ in

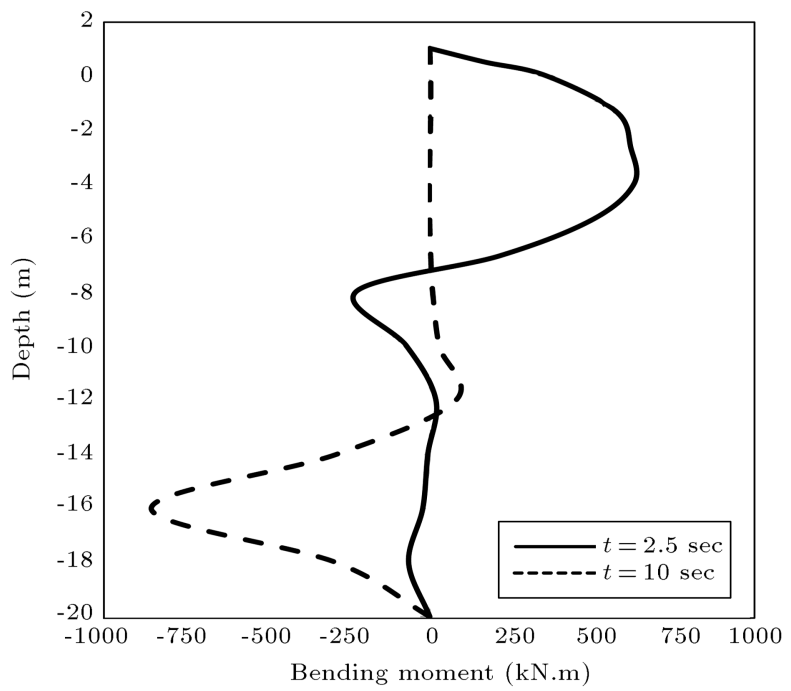

Figure 34. Maximum bending moments in pile, $f=2 \mathrm{~Hz}$, Case II with $T h=8 \mathrm{~m}$.

$t=10 \mathrm{sec}$ according to Figure 34 . Its amount is $37 \%$ greater compared to Case II with $T h=4$ and $45 \%$ larger than Case I (after liquefaction). The reason is the presence of a thick clay layer causing liquefaction to penetrate down into deeper layers. Therefore, kinematic forces of soil applied to the pile spread down to lower points of ground.

\subsubsection{Effect of loading frequency}

Based on the comparison of Figures 32 with 35 and Figures 33 with 36 , pile MBM decreases with an increase in frequency of base excitation in general, and its location transfers to shallower depths. For Case I with $f=2 \mathrm{~Hz}, \mathrm{MBM}$ in pile is nearly $230 \%$ greater than its amount for $f=5 \mathrm{~Hz}$. For Case II, the extent of such an increase is up to $360 \%$. This result is in accordance with the discussion regarding

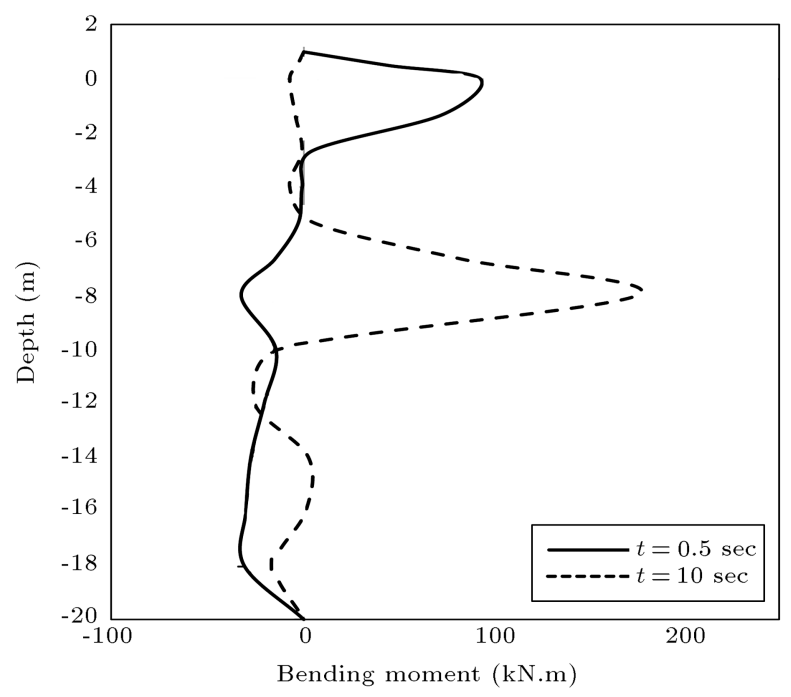

Figure 35. Bending moments in pile at $t=0.5$ and $10 \mathrm{sec}$ for base excitation with $f=5 \mathrm{~Hz}$ for Case I. 


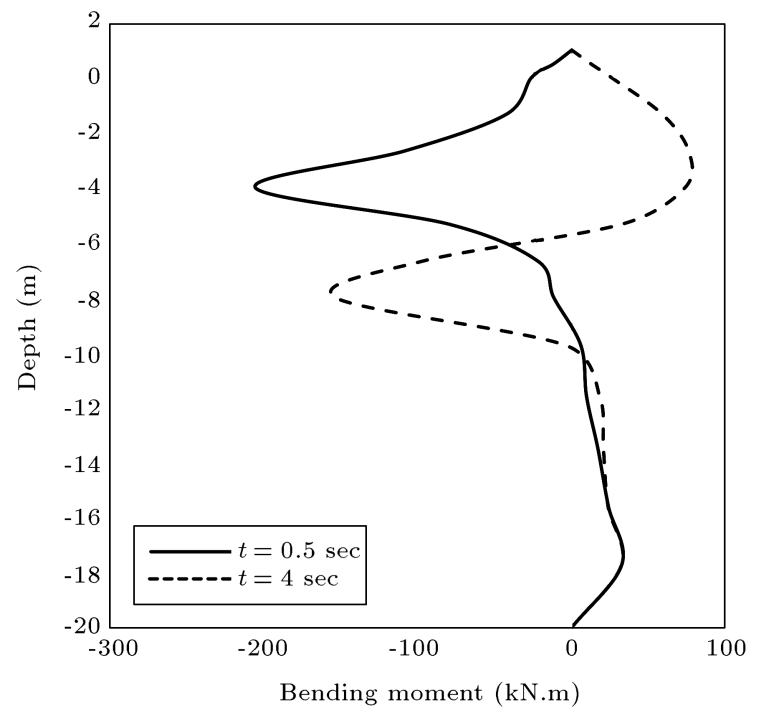

Figure 36. Bending moments in pile at $t=0.5$ and $4 \mathrm{sec}$ for base excitation with $f=5 \mathrm{~Hz}$ for Case II.

soil displacements and $R_{u}$ under different frequencies of loading.

\subsubsection{Effect of loading $P G A$}

By noticing Figures 37 to 40, several points could be derived. First, an increase in PGA of loading from $0.15 \mathrm{~g}$ to $0.25 \mathrm{~g}$ yields a rise in the value of MBM following the liquefaction. For instance, MBM increases up to $17 \%$ for Case I when $f=2 \mathrm{~Hz}$ and $15 \%$ for Case II. For loading with $f=5 \mathrm{~Hz}, \mathrm{MBM}$ increases up to $60 \%$ for Case I and $66 \%$ for Case II. Therefore, it is obvious that MBM increases with a rise in PGA for all cases.

For loadings with larger frequencies, an increase in PGA causes a greater rise in MBM, which is apparent

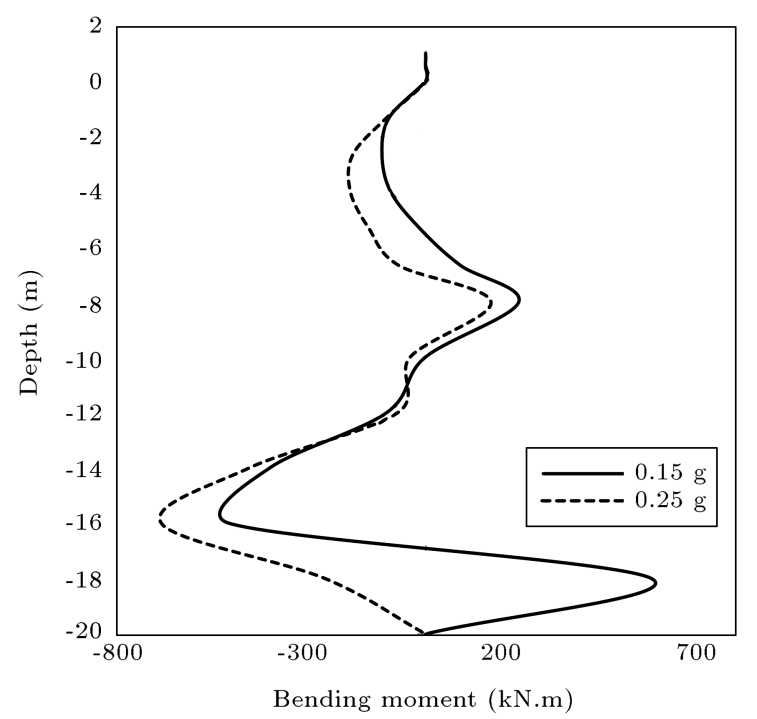

Figure 37. Comparison of the distribution of maximum bending moment of pile under base excitation with $f=2 \mathrm{~Hz}$ for $\mathrm{PGA}=0.15 \mathrm{~g}$ and $0.25 \mathrm{~g}$ for Case $\mathrm{I}$.

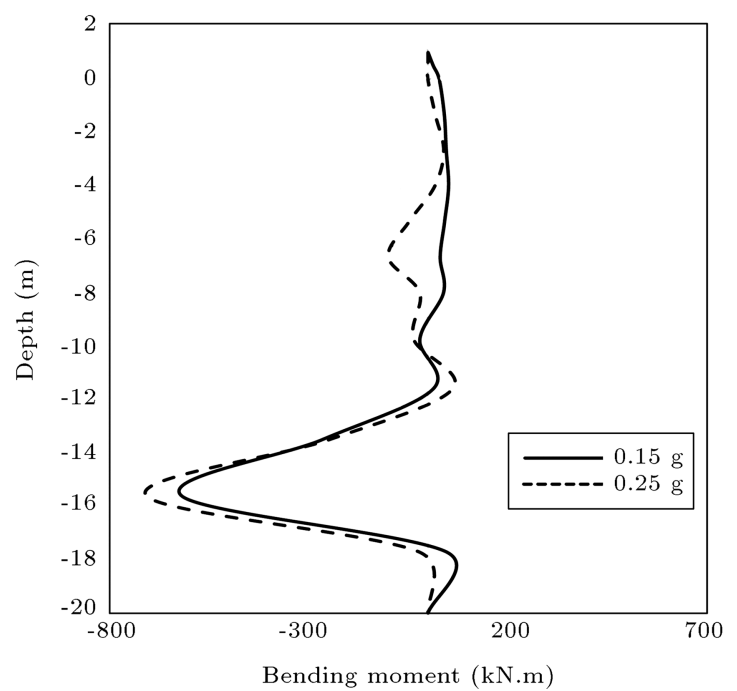

Figure 38. Comparison of the distribution of maximum bending moment of pile under base excitation with $f=2 \mathrm{~Hz}$ for $\mathrm{PGA}=0.15 \mathrm{~g}$ and $0.25 \mathrm{~g}$ for Case II.

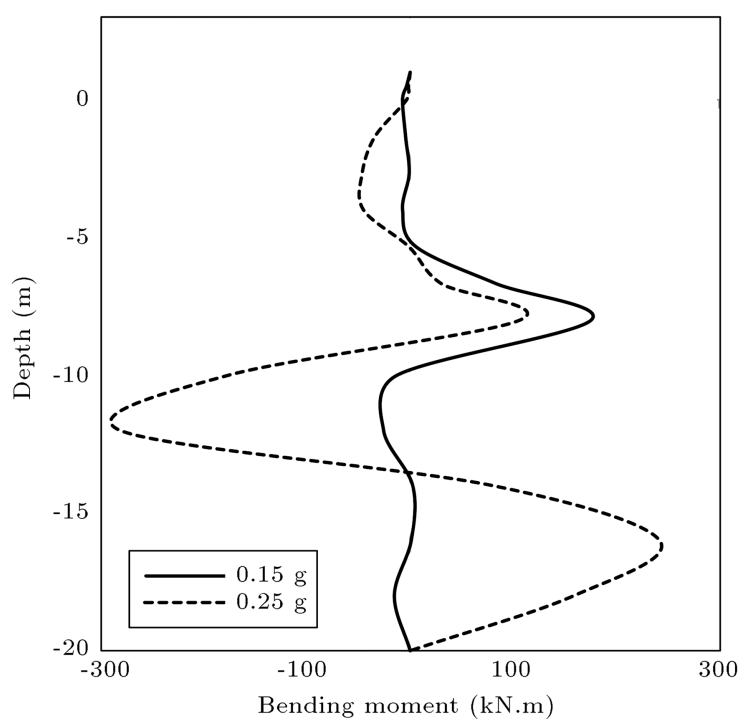

Figure 39. Comparison of the distribution of maximum bending moment of pile under base excitation with $f=5 \mathrm{~Hz}$ for $\mathrm{PGA}=0.15 \mathrm{~g}$ and $0.25 \mathrm{~g}$ for Case $\mathrm{I}$.

for both cases. Based on the discussions presented in the previous sections, it is concluded that the increase of $R_{u}$ is of very slight amount for deeper zones for loading with greater frequencies; therefore, soil will remain stronger in terms of shear strength. However, intensification of PGA comes along with a greater rise in $R_{u}$ at such depths. Thus, substantial loss in soil strength takes place, meaning that a longer part of the embedded pile acts as free length and pile experiences larger bending moments at the mentioned zone.

\subsubsection{Effect of pile $L / D$}

According to Figure 41 for Case I, distribution of pile bending moments is the same for $L / D=20$ and $L / D=$ 


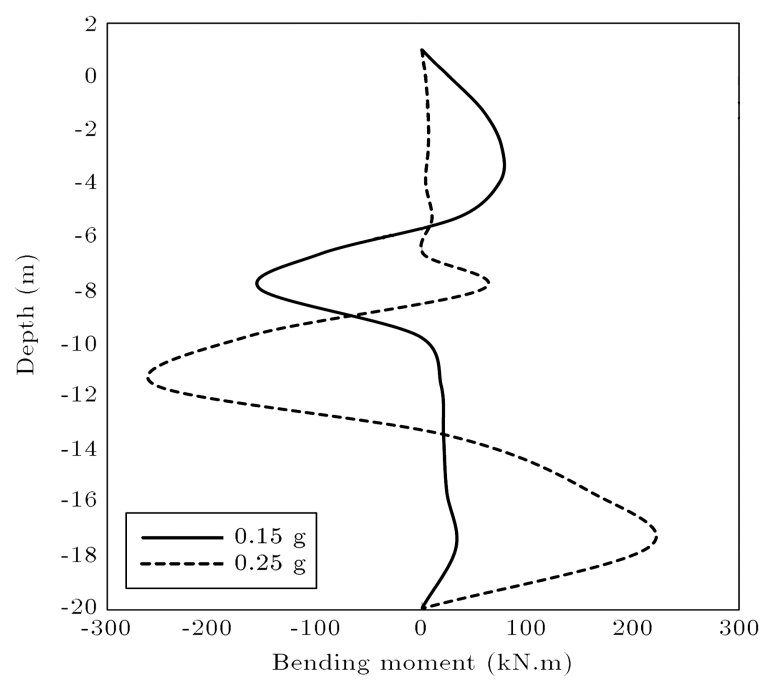

Figure 40. Comparison of the distribution of maximum bending moment of pile under base excitation with $f=5 \mathrm{~Hz}$ for $\mathrm{PGA}=0.15 \mathrm{~g}$ and $0.25 \mathrm{~g}$ for Case II.

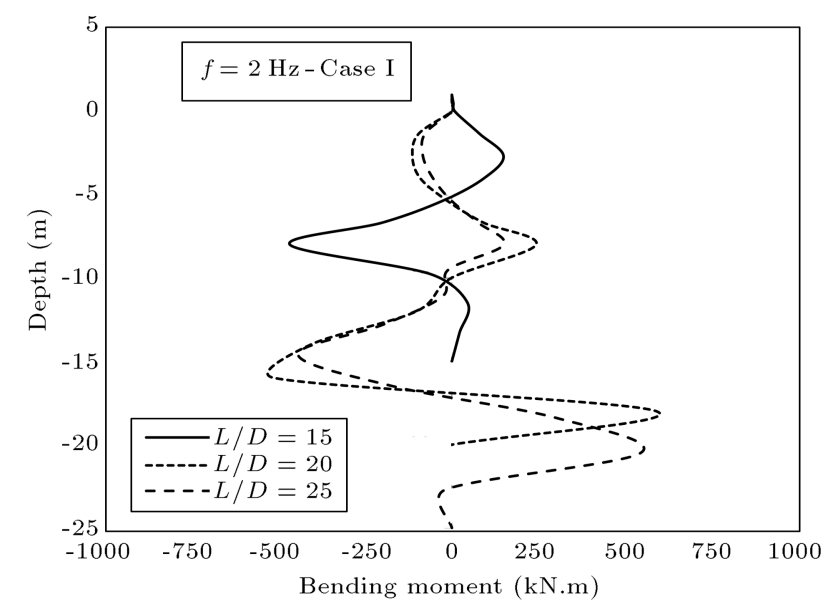

Figure 41. Comparison of pile maximum bending moment in depth for different $L / D s$.

25 , and their maximum values occur nearly at similar depths. For $L / D=15, \mathrm{MBM}$ is $20 \%$ smaller in value and is located at an upper level. However, it has been previously concluded that short pile may experience total instability due to insufficient fixed length inside denser layer, and it is recommended to extend pile into denser sections of soil to reach a reliable base point. Similar results are also discovered for Case II.

\subsubsection{Effect of clay stiffness}

According to Figure 42, MBM is approximately equal for soft and stiff clays for case of $f=2 \mathrm{~Hz}$ after liquefaction. However, comparison of displacement figures for $f=2 \mathrm{~Hz}$, as discussed in the preceding sections, indicates that maximum displacements of pile head for soft clay are $50 \%$ larger than their value for the case of stiff clay. Both of the mentioned quantities have resulted prior to occurrence of liquefaction, the

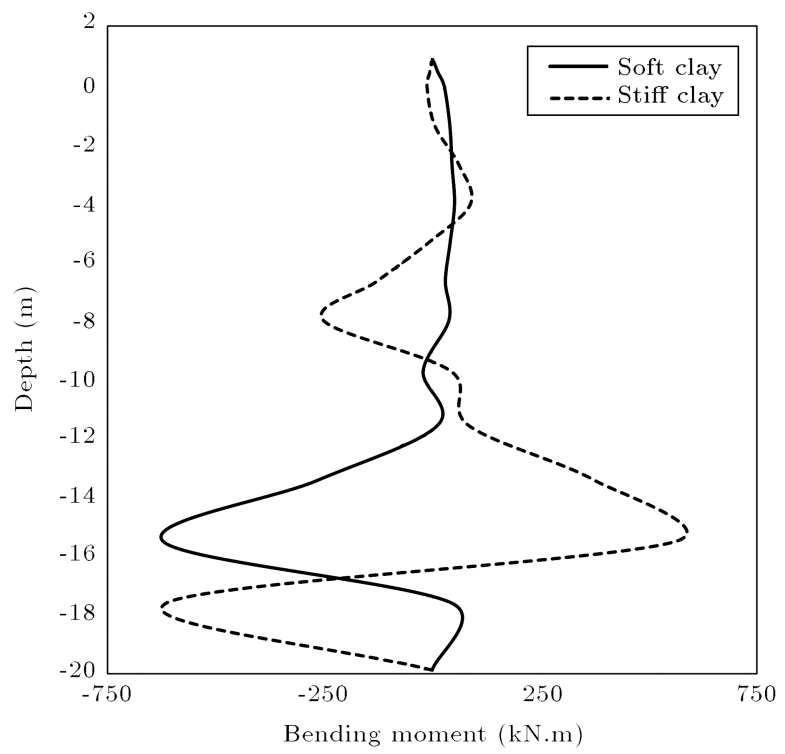

Figure 42. Comparison of maximum bending moment in pile for soft and stiff clays, $f=2 \mathrm{~Hz}$, Case II.

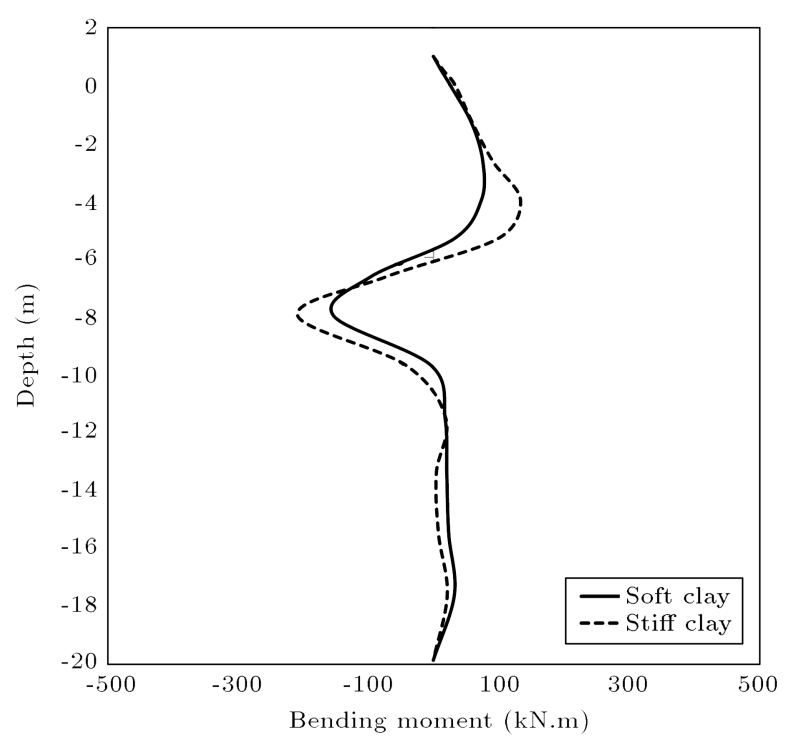

Figure 43. Comparison of maximum bending moment in pile for soft and stiff clays, $f=5 \mathrm{~Hz}$, Case II.

reason of which is severe softness of clay. However, displacement of pile for both cases becomes equal after liquefaction and stiffness of upper layer becomes a less influencing factor in the ultimate displacements.

When $f=5 \mathrm{~Hz}, \mathrm{MBM}$ of pile for the case containing a layer of stiff clay increases $35 \%$ relative to soft clay according to Figure 43.

For small frequency $(f=2 \mathrm{~Hz}$ in Figure 42), liquefaction occurs up to deeper parts in the soil. Clay does not apply notable kinematic forces to pile when it is very soft. Consequently, large moment only gets restricted to deeper parts of pile. When clay is stiffer, it restrains its adjacent pile zones from a free move and a peak appears in the figure for this situation. In 
the case of greater frequency $(f=5 \mathrm{~Hz}$ in Figure 43), only upper zones of soil are liquefied, and hence, similar patterns are predictable for both soft and stiff clays.

\subsubsection{Influence of the superstructure mass}

By considering the entire period of loading, MBM of the pile has not been considerably affected by the increase in superstructure mass. The reason is that maximum value of pile bending moments occurs in deeper points after liquefaction under the effect of kinematic forces applied to upper soil layers. However, the increase of superstructure mass causes MBM to increase up to $100 \%$ at some regions near ground surface based on Figures 44 and 45 . In other words, for most cases, MBM is not affected by the superstruc-

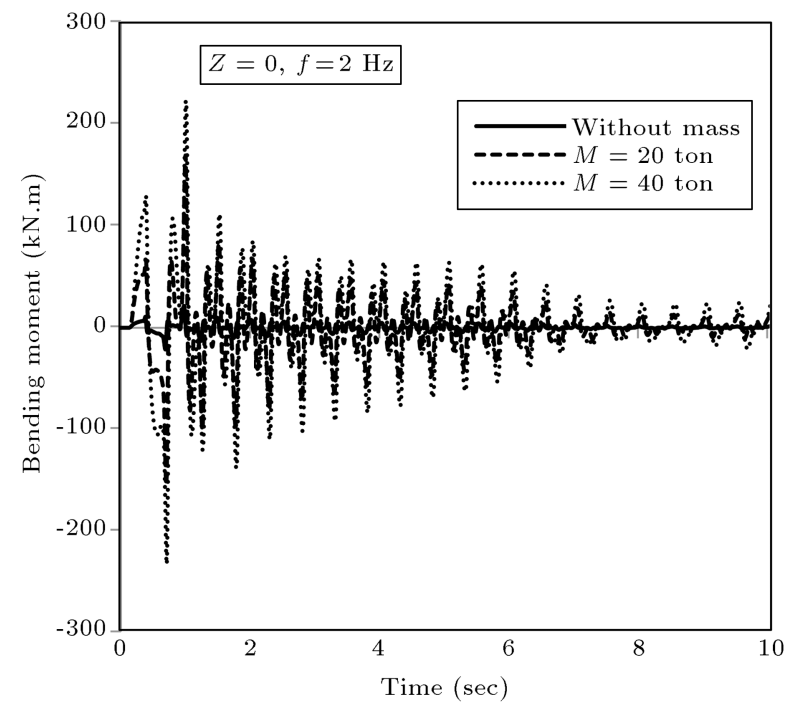

Figure 44. Comparison of pile bending moment's time history at ground surface in Case I for superstructure masses of 0,20 , and 40 tons.

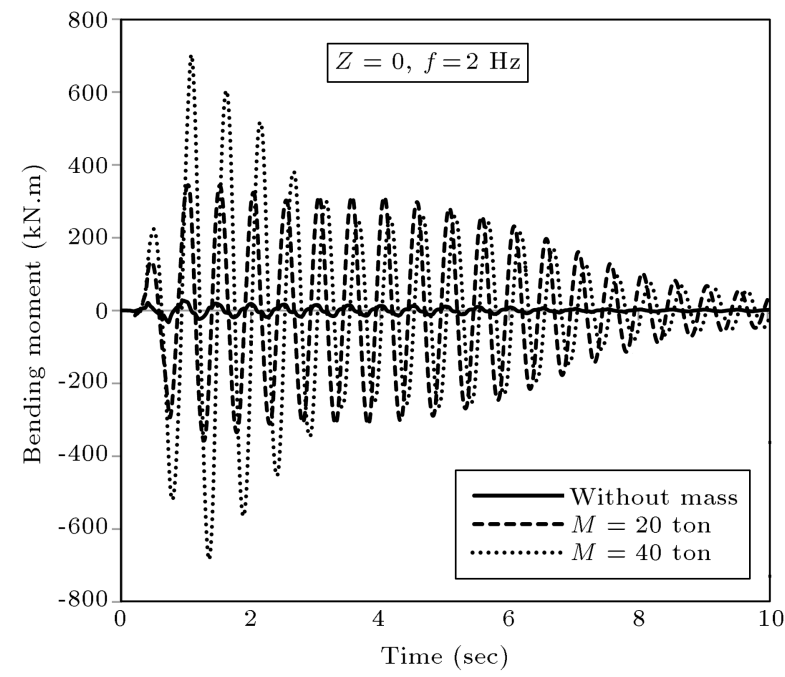

Figure 45. Comparison of pile bending moment's time history at ground surface in Case II for superstructure masses of 0,20 , and 40 ton. ture mass and its value is mainly dominated by the ground kinematic forces after initiation of liquefaction. However, the mass of superstructure is very great in this study, and the increase in MBM occurs before liquefaction and is not due to liquefaction. When superstructure mass doubles, MBM will also double.

\section{Concluding remarks}

The main findings of the numerical analyses, including the investigation of different parameters affecting soilpile interaction behavior for large diameter piles considering possibility of soil liquefaction, can be summarized as follows:

- If the excitation frequency is equal to or less than soil natural frequency, it will be more probable for deeper zones of soil to liquefy, in addition to the liquefaction of upper layers. Therefore, it is recommended to select a longer pile and increase its embedment length in such conditions;

- When frequency of excitation is high, it takes longer time for liquefaction to take place. In other words, if an excitation with high frequency is applied for a longer period of time, it can have a similar effect on loadings with lower frequencies;

- When a layer of cohesive material is placed over a relatively loose layer of sand, sand layer will possibly liquefy in a shorter period of time. $R_{u}$ will rise to a value greater than 1 and sand loses its shear strength. Responses of an embedded pile will be intensified accordingly;

- If clay covers the loose sand bed, maximum pile head displacement could rise to $50 \%$ larger than the condition with no clay. This maximum occurs before liquefaction due to the extremely high softness of the clay layer;

- When a layer of soft clay soil is placed over the sand layer, MBM of the pile could possibly increase up to $45 \%$ after liquefaction, which is dependent on thickness of clay layer;

- Stiffness of stratum, containing cohesive material, affects MBM and displacement of the pile. When frequency is low in the case of stiff clay, bending moment figure has three peaks. However, their values are nearly equal. For higher frequencies, bending moment has a similar pattern for both cases, along with a 35\% increase for stiffer clay;

- The vibrational behavior of pile after liquefaction is under influence of superstructure inertial forces and soil kinematic forces as well; simultaneous effect of these two factors can cause an increase in the loads applied to the pile;

- Peak displacement of pile head is strongly dependent 
on frequency of base excitation and increases with reduction in frequency. For example, when $f=$ $1 \mathrm{~Hz}$, maximum displacement is 15 times greater than the case with $f=10 \mathrm{~Hz}$;

- An increase in pile diameter, and subsequently its lateral area can lead to a reduction in displacement of pile head because of its rigidity. On the other hand, there will be a rise in soil kinematic forces after liquefaction due to the increase in its lateral area, which could possibly induce larger overall displacements to the pile;

- With an increase in the loading frequency, pile MBMs decline in general. For Case I with $f=2 \mathrm{~Hz}$ in this study, it is observed that MBM of pile is $230 \%$ larger compared to its value for $f=5 \mathrm{~Hz}$. For Case II, it is intensified up to $360 \%$;

- Increasing PGA from $0.15 \mathrm{~g}$ to $0.25 \mathrm{~g}$ results in a $66 \%$ growth rate in pile bending moment in loading with $f=5 \mathrm{~Hz}$. This increase is only $17 \%$ for loading with $f=2 \mathrm{~Hz}$;

- Changing pile length without altering its diameter has only slight influence on maximum displacement of pile head. However, shorter piles may experience overall instability due to insufficient fixed length through denser layer. Therefore, it is recommended to extend pile into denser regions of ground to obtain a reliable supporting point;

- As the peak of MBM is dominated by soil kinematic forces after liquefaction, size of superstructure mass does not tend to have a considerable effect on MBM of pile during loading period. However, for some regions near ground surface, the increase of superstructure mass can increase MBM locally;

- Liquefaction of soil layers above the static neutral plane will have a minor effect on the pile regardless of the magnitude of the liquefaction-induced settlement [44]. In the current research, liquefaction zone is always above the neutral plane and its effect is negligible on induced axial force in the pile.

\section{References}

1. Yen, W.H.P., Chen, G., Buckle, I., Allen, T., Alzamora, D., Ger, J. and Arias, J.G., Postearthquake Reconnaissance Report on Transportation Infrastructure Impact of the February 27, 2010, Offshore Maule Earthquake in Chile, U.S. Department of Transportation, Federal Highway Administration, McLean, VA (2011).

2. Wilson, D.W. "Soil-pile-superstructure interaction in liquefying sand and soft clay", Ph.D. Dissertation, University of California at Davis (1998).

3. Kamijo, N., Saito, H., Kusama, K., Kontani, O. and Nigbor, R. "Seismic tests of a pile-supported structure in liquefiable sand using large-scale blast excitation",
Nuclear Engineering and Design, 228(1-3), pp. 367376 (2004).

4. Yao, Sh., Kobayashi, K., Yoshida, N. and Matsuo, H. "Interactive behavior of soil-pile-superstructure system in transient state to liquefaction by means of large shake table tests", Soil Dynamics and Earthquake Engineering, 24(5), pp. 397-409 (2004).

5. Tokimatsu, K., Suzuki, H. and Sato, M. "Effect of dynamic soil-pile structure interaction on pile stresses", J. Struct. Constr. Eng., Arch. Inst. Jpn., 587, pp. 125$132(2005)$.

6. Dungca, J.R., Kuwando, J., Saruwatari, T., Izawa, J., Suzuki, H. and Tokimatsu, K. "Shaking table tests on the lateral response of a pile buried in liquefied sand", Soil Dynamics and Earthquake Engineering, 26(2-4), pp. 287-295 (2006).

7. Tamura, Sh. and Tokimatsu, K. "Seismic earth pressure acting on embedded footing based on large-scale shaking table tests", Geotechnical SP, ASCE, 145, pp. 83-96 (2006).

8. Han, J.T., Kim, S.R., Hwang, J.I. and Kim, M.M. "Evaluation of the dynamic characteristics of soilpile system in liquefiable ground by shaking table tests", In 4th International Conference on Earthquake Geotechnical Engineering, Paper No. 1340, Thessaloniki, Greece (2007).

9. Haeri, S.M., Kavand, A., Rahmani, I. and Torabi, H. "Response of a group of piles to liquefaction-induced lateral spreading by large scale shake table testing", Soil Dynamics and Earthquake Engineering, 38, pp. 25-45 (2012).

10. Brandenberg, S.J., Boulanger, R.W., Kutter, B.L. and Chang, D. "Behavior of pile foundations in laterally spreading ground during centrifuge tests", Journal of Geotechnical and Geoenvironmental Engineering, 131(11), pp. 1378-1391 (2005).

11. Finn, W.D.L., Thavaraj, T. and Fujita, N. "Piles in liquefiable soils: seismic analysis and design issues", in Proc., 10th Int. Conf. on Soil Dynamics and Earthquake Engineering, Philadelphia (2001).

12. Tabesh, A. and Poulos, H.G. "A simple method for the seismic analysis of piles and its comparison with the results of centrifuge tests", in Proc. 12th World Conf. on Earthquake Engineering, Auckland, New Zealand (2000).

13. Miyazaki, M., Ishizaki, S. and Tokimatsu, K. "Effective stress analysis of pile foundations showing various damage patterns in liquefied deposits during 1995 Hyogoken-Nambu earthquake", in 4th International Conference on Recent Advances in Geotechnical Earth (2001).

14. Finn, W.D.L. and Fujita, N. "Pile in Liquefiable soils: seismic analysis and design issues", Soil Dynamics and Earthquake Engineering, 22(9-12), pp. 731-742 (2002).

15. Klar, A., Baker, R. and Frydman, S. "Seismic soilpile interaction in liquefiable soil", Soil Dynamics and Earthquake Engineering, 24(8), pp. 551-564 (2004). 
16. Liyanapathirana, D.S. and Poulos, H.G. "A numerical model for seismic analysis of piles in liquefying Soil", in International Deep Foundations Congress, Orlando, Florida, United States (2002).

17. Liyanapathirana, D. and Poulos, H.G. "Pseudostatic approach for seismic analysis of piles in liquefying soil", Journal of Geotechnical and Geoenvironmental Engineering, 131(12), pp. 1480-1487 (2005).

18. Chang, D.W., Lin, B.S. and Cheng, S.H. "Dynamic pile behavior affecting by liquefaction from EQWEAP analysis", in 4th International Conference on Earthquake Geotechnical Engineering, Thessaloniki, Greece (2007).

19. Bhattacharya, S., Dash, S., Mitra, N., Adhikari, S. and Blakeborough, A. "Investigation of bending-buckling interaction of piles in liquefiable soils", in 14th WCEE, Beijing, China (2008).

20. Elgamal, A., He, L., Lu, J., Abe, A., Abdoun, T., Dobry, R., Sato, M., Tokimatsu, K. and Shantz, T. "Liquefaction-induced lateral load on piles", in 4 th International Conference on Earthquake Engineering, Paper No. 42, Taipei, Taiwan (2006).

21. Cheng, Zh. and Jeremic, B. "Numerical modeling and simulation of pile in liquefiable soil", Soil Dynamics and Earthquake Engineering, 29(11-12), pp. 1405-1416 (2009).

22. Cubrinovski, M., Uzuoka, R., Sugita, H., Tokimatsu, K., Sato, M., Ishihara, K., Tsukamoto, Y. and Kamata, T. "Prediction of pile response to lateral spreading by 3-D soil-water coupled dynamic analysis: Shaking in the direction of ground flow", Soil Dynamics and Earthquake Engineering, 28(6), pp. 421-435 (2008).

23. Rahmani, A. and Pak, A. "Dynamic behavior of pile foundations under cyclic loading in liquefiable soils", Computers and Geotechnics, 40, pp. 114-126 (2011).

24. Asgari, A., Oliaei, M. and Bagheri, M. "Numerical simulation of improvement of a liquefiable soil layer using stone column and pile-pinning techniques", Soil Dynamics and Earthquake Engineering, 51, pp. 77-97 (2013).

25. Sarkar, R., Bhattacharya, S. and Maheshwari, B.K. "Seismic requalification of pile foundations in liquefiable soils", Indian Geotechnical Journal, 44(2), pp. 183-195 (2014).

26. Bouckovalas, G. and Chaloulos, Y. "Kinematic interaction of piles in laterally spreading ground", Bulletin of Earthquake Engineering, 12(3), pp. 1221-1237 (2014).

27. Asaadi, A. and Sharifipour, M. "Numerical simulation of liquefaction susceptibility of soil interacting by single pile", International Journal of Mining and GeoEngineering, 49(1), pp. 47-56 (2015).

28. Lin, H., Ni, L., Suleiman, M. and Raich, A. "Interaction between laterally loaded pile and surrounding soil", Journal of Geotechnical and Geoenvironmental Engineering, 141(4), pp. 1168-1179 (2015).
29. Elgamal, A. and Yang, Zh. "Sand boils and liquefaction-induced lateral deformation", in 15th Intl. Conference on Soil Mechanics and Geotechnical Engineering, Istanbul,Turkey (2001).

30. Parra, E. "Numerical modeling of liquefaction and lateral ground deformation including cyclic mobility and dilation response in soil systems", $\mathrm{PhD}$ Thesis, Dept. of Civil Engineering, Rensselaer Polytechnic Institute, Troy, NY. (1996).

31. Yang, Zh. "Numerical modeling of earthquake site response including dilation and liquefaction, $\mathrm{PhD}$ Thesis", Dept. of Civil Engineering and Engineering Mechanics, Columbia University, New York. (2000).

32. Prevost, J.H. "A simple plasticity theory for frictional cohesionless soils", International Journal of Soil Dynamics and Earthquake Engineering, 4(1), pp. 9-17 (1985).

33. Iwan, W.D. "On a class of models for the yielding behavior of continuous and composite systems", Journal of Applied Mechanics, 34(3), pp. 612-617 (1967).

34. Mróz, Z. "On the description of anisotropic workhardening", Journal of the Mechanics and Physics of Solids, 15(3), pp. 163-175 (1967).

35. Elgamal, A., Yang, Zh., Parra. E. and Ragheb, A. "Modeling of cyclic mobility in saturated cohesionless soils", International Journal of Plasticity, 19(6), pp. 883-905 (2003).

36. Dafalias, Y.F. "Overview of constitutive model used in VELACS, verifications of numerical procedures for the analysis of soil liquefaction problems", Arulanandan Scott, Rotterdam, Balkema (1993).

37. Elgamal, A.W., Parra, E., Yang, Z., Dobry, R. and Zeghal, M. "Liquefaction constitutive model", in Physics and Mechanics of Soil Liquefaction Symposium, Balkema, Rotterdam, The Netherlands (1999).

38. Elgamal, A., Lu, J., Yang, Zh. and Shantz, T. "A 3D soil-structure interaction computational framework", in 5th International Conference on Earthquake Engineering, Tokyo, Japan (2010).

39. Lu, J., Elgamal, A. and Yang, Zh., OpenSeesPL User Manual, University of California, San Diego, Department of Structural Engineering (2011).

40. Uncuoglu, E. and Laman, M. "Lateral resistance of a short rigid pile in a two-layer cohesionless soil", Acta Geotechnica Slovenica, 2, pp. 19-43 (2011).

41. Cubrinovski, M., Kokusho, T. and Ishihara, K. "Interpretation from large-scale shake table tests on piles undergoing lateral spreading in liquefied soils", Soil Dynamics and Earthquake Engineering, 26(2-4), pp. 275-286 (2006).

42. de Groot, M.B., Bolton, M.D., Foray, P., Meijers, P., Palmer, A.C., Sandven. R. and Sawicki, A. "Physics of liquefaction phenomena around marine structures", Journal of Waterway, Port, Coastal and Ocean Engineering, ASCE, 132, pp. 227-243 (2006).

43. Lu, C.W., Oka, F. and Zhang, F. "Analysis of soil- 
pile-structure interaction in a two-layer ground during earthquakes considering liquefaction", International Journal for Numerical and Analytical Methods in Geomechanics, 32(8), pp. 863-895 (2007).

44. Fellenius, B.H. and Siegel, T.C. "Pile drag load and downdrag in a liquefaction event", Journal of Geotechnical and Geoenvironmental Engineering, 134(9), pp. 1412-1416 (2008).

\section{Biographies}

Mohammad Oliaei is an Assistant Professor of Civil Engineering. He joined the geotechnical group in the Department of Civil Engineering, Tarbiat Modares University in 2008. He graduated in $\mathrm{PhD}$ from Sharif University of Technology (2007) as the first rank student. In 2005, he was awarded a scholarship from British Council to continue his $\mathrm{PhD}$ study at Cambridge University. He specializes in the area of Geotechnical Engineering and Numerical Modelling. He is the reviewer of some ISI and Scientific \& Technical Journals.

Seyed Mohammad Amin Ghotbi Siabil is currently a $\mathrm{PhD}$ candidate in Geotechnical Engineering, K.N. Toosi University of Technology, Tehran, Iran. He received his MSc degree in Geotechnical Engineering, from Tarbiat Modares University, Tehran, Iran. He also received his BS degree in Civil Engineering, from Amirkabir University of Technology, Tehran, Iran. His research interests include numerical and experimental investigations of foundations, geosynthetics engineering, dynamic soil-structure interaction and liquefaction. 